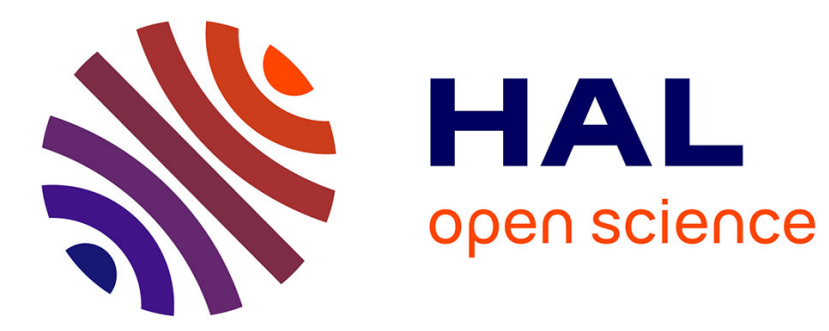

\title{
Malaria and Education: Evidence from Mali
}

Josselin Thuilliez, Hippolyte d'Albis, Hamidou Niangaly, Ogobara Doumbo

\section{To cite this version:}

Josselin Thuilliez, Hippolyte d'Albis, Hamidou Niangaly, Ogobara Doumbo. Malaria and Education: Evidence from Mali. 2016. halshs-01278041

\section{HAL Id: halshs-01278041 https://shs.hal.science/halshs-01278041}

Submitted on 23 Feb 2016

HAL is a multi-disciplinary open access archive for the deposit and dissemination of scientific research documents, whether they are published or not. The documents may come from teaching and research institutions in France or abroad, or from public or private research centers.
L'archive ouverte pluridisciplinaire HAL, est destinée au dépôt et à la diffusion de documents scientifiques de niveau recherche, publiés ou non, émanant des établissements d'enseignement et de recherche français ou étrangers, des laboratoires publics ou privés. 


\section{Documents de Travail du

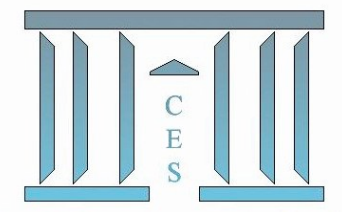

Malaria and Education: Evidence from Mali

Josselin THUILLIEZ, Hippolyte d'AlBIS,

Hamidou Niangaly, Ogobara Doumbo

2016.09

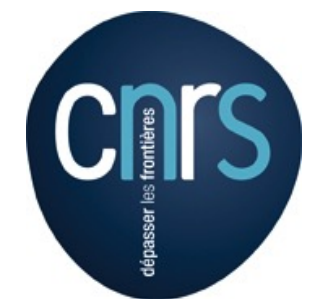




\title{
Malaria and Education: Evidence from Mali.*
}

\author{
Josselin Thuilliez ${ }^{\dagger} \quad$ Hippolyte d’Albis ${ }^{\ddagger} \quad$ Hamidou Niangaly ${ }^{\S}$ \\ Ogobara Doumbo
}

February 3, 2016

\footnotetext{
*We are very grateful to Hoyt Bleakley, Lauwrence Katz, Maria Kuecken, Nigel Rice, Andrew Street, Marie-Anne Valfort, and numerous seminar participants for helpful comments and advice. We especially thank the children of Diankabou and their families for their cooperation. We are also grateful to Diankabou school teachers, the Malaria Research and Training Center employees for expert research assistance, for help acquiring the necessary data and for answering our many questions. In particular, we would like to thank Pr. Abdoulaye Djimdé, Dr. Alasseini Balam, Dr. Yamoussa Keita, Dr. Abdoul Karim Sangaré, Saïla Doumbo, Ismaila Théra; and the Department of Immunology of Stockholm University, especially Stéphanie Boström, Leif Rogell and Marita Troye Blomberg. We thank the European Research Council (ERC Starting Grant DU 283953), the French School of Public Health, the Fondation pour les Études et Recherches sur le Développement International, and University Paris 1 for financial support. This work also benefited from the support of the French National Research Agency, as part of the program "Investissements d'avenir", ANR-10-LABX-14-01. The usual caveat applies.

${ }^{\dagger}$ CNRS - University Paris 1. E-mail: josselin.thuilliez@univ-paris1.fr

${ }^{\ddagger}$ Paris School of Economics - University Paris 1. E-mail: hdalbis@psemail.eu

$\S$ Malaria Research and Training Center - University of Bamako. E-mail: hniangaly@icermali.org

『Malaria Research and Training Center - University of Bamako. E-mail: okd@icermali.org
} 


\begin{abstract}
This article examines the influence of malaria on human capital accumulation in the village of Diankabou in Mali. To account for malaria endogeneity and its interaction with unobservable risk factors, we exploit natural variations in malaria immunity across individuals of several sympatric ethnic groups - the Fulani and the non-Fulani - who differ in their susceptibility to malaria. The Fulani are known to be less susceptible to malaria infections, despite living with a similar malaria transmission intensity to those seen among other ethnic groups. We also use natural variation of malaria intensity in the area (during and after the malaria transmission season) and utilize this seasonal change as a treatment. We find that malaria has an impact on cognitive and educational outcomes in this village. We discuss the implications of this result for human capital investments and fertility decisions with the help of a quantity-quality model.

Keywords: Malaria, Immunity, Education, Cognition, Fertility
\end{abstract}

JEL: O12, I15, I25 


\section{Introduction}

Malaria is considered to be among the oldest of human diseases with profound impact on human evolution. Indeed, the "malaria hypothesis" posits that certain human genetic polymorphisms ${ }^{1}$ have been naturally selected in high frequencies because they have protected against the effects of malaria infections. Such protection involves the immune system, i.e. the ability of an organism to resist disease ${ }^{2}$. Moreover, the employment of such defense mechanisms against malaria is recognized as a costly life-history trait (Williams, 2006). For instance it is well known that inherited conditions such as sickle cell anaemia and betathalassaemia, which cause deformities in red blood cells and are common in people from malaria regions, make it more difficult for malaria parasites to infect red blood cells.

Though tentative, our investigation exploits immunity to malaria in an attempt to explain the effects of malaria on human capital accumulation. One of the possible approaches in the study of human variation in the susceptibility to malaria compares malariological indicators between populations that differ in their genetic background but living in the same epidemiological context, i.e., exposed to the same transmission level and to the same parasite strains. The possible observation of inter-ethnic differences of susceptibility in such conditions provides an opportunity to detect factors associated with protection (Modiano et al., 1995, 2001). In Sub-Saharan Africa, and in Mali specifically, the Fulani ethnic group has proved to be less susceptible to malaria ${ }^{3}$ as reflected by their lower parasite rate (the proportion of the population found to carry asexual blood-stage parasites), their lower parasitemia (the quantitative content of parasites in the blood) and the fewer clinical symptoms that they exhibit when compared to than other sympatric ethnic groups (Dolo et al., 2005; Farouk et al., 2005). Sympatric in this context refers to the fact that they inhabit the same

\footnotetext{
${ }^{1}$ The recurrence within a population of two or more discontinuous genetic variants of a specific trait.

${ }^{2}$ The immune system is the collection of cells, tissues and molecules that protects the body from numerous pathogenic microbes and toxins in our environment. Such defense can be divided into two general types of reactions: reactions of innate immunity and reactions of adaptive immunity. The innate system is the first line of defense and comprises mechanisms that defend the host from infection by other organisms in a nonspecific manner. The adaptive immune system, or acquired immune system, is specialized and eliminates or prevents pathogen growth. In acquired immunity, pathogen-specific receptors are "acquired" during the lifetime of the organism.

${ }^{3}$ Four species of these protozoan parasites account for almost all infections seen in humans: Plasmodium falciparum, Plasmodium vivax, Plasmodium ovale and Plasmodium malariae. Plasmodium falciparum is the most aggressive of all and accounts for the majority of infections in Africa. Malaria stands for Plasmodium falciparum malaria in this article.
} 
overlapping geographical area but the gene pools are not mixed. Therefore, we use this fact to identify the possible impacts of malaria on cognition and on education at the pupil level and we use it to understand the complex links between infection, educational investment and fertility at the household level.

Our analysis is divided into two main parts. First, we study the direct impact of malaria on educational outcomes. In the area we consider, there are two ethnic groups (Fulanis and non-Fulanis) and two seasons (high and low malaria transmission seasons). The Fulani have some immunity to malaria so that their infection rates are much lower when compared to those seem among the non-Fulani during the high season. However, they are comparable during the low season. Given this, by comparing the change in cognitive and educational scores across seasons between the Fulani and the non-Fulani, and rescaling this change based on the difference in infection rate changes across ethnic groups, one can assess the specific impact of malaria on cognitive and educational scores.

We improve upon the literature in two ways: (i) Improving the measurement of malaria by using a polymerase chain reaction $(\mathrm{PCR})^{4}$, and (ii) Assessing a "natural" treatment effect and potential coping mechanisms. Cognitive outcomes are Raven Progressive Matrices tests scores (Raven, 1984). Educational achievement outcomes, on the other hand are measured with a set of educational variables taken from previous studies (Jukes et al., 2006; Thuilliez et al., 2010) as well as French models for primary educational tests (BatelemR and Boehm3).

We find that malaria and notably asymptomatic malaria (i.e., the infection without any symptoms) have an impact on cognitive and educational outcomes in Diankabou, the village used in this study, located in the North of Mali. These results are in line with Venkataramani (2012) for cognition and Bleakley (2010b), Cutler et al. (2010), Lucas (2010) or Barofsky, Anekwe and Chase (2015) for literacy rates or years of educational attainment. Moreover, although we focus on short-run impacts and the external validity of our study is limited

\footnotetext{
${ }^{4} \mathrm{PCR}$ (polymerase chain reaction) is a technique in molecular genetics that permits the analysis of any short sequence of DNA (or RNA), even in samples containing only minute quantities of DNA or RNA. PCR is used to reproduce (amplify) selected sections of DNA or RNA for analysis. PCR is now extensively used for malaria diagnosis as PCR can distinguish between the different species of human malaria parasites. When used in the best possible conditions, the PCR technique has been reported capable of detecting parasitaemia of less than $0.00002 \%$, which corresponds to one parasite per mm3, or 5 parasites per $5 \mathrm{l}$ sample of blood. By comparison, microscopy has been reported capable of detecting parasitaemia of $0.0001 \%$. PCR is therefore much more sensitive and specific than microscopy, generally used in other microeconomic studies. Put differently, PCR is more specific and sensitive than previous techniques used such as microscopy (Anchinmane and Shedge, 2011)
} 
to the place of study, we improve the understanding of potential competing mechanisms. As Angus Deaton has observed, even though such studies do not have the righteousness of randomization they do concern actual policies playing out in a real life environment (Deaton, 2010).

We discuss the long-run economic implications of this result by considering a quantityquality model where parents choose their fertility and their investment in the education of their surviving children. The framework is similar to Ehrlich and Lui (1991), Kalemli-Ozcan (2003), Lagerlöf (2003), Cervellati and Sunde (2005), Estevan and Baland (2007), Bell and Gersbach (2009) and Baudin (2012), except that we focus on early child mortality, which occurs before the schooling period, and distinguish it from child morbidity. The main novelty here is that we consider a differential exposure to malaria between the Fulani and non-Fulani ethnic groups. The model also explores the potential cost of immunity for populations at a lower risk of disease, when the disease reduces the returns to education. It shows that if malaria increases the child mortality rate and reduces educational outcomes, the unprotected group (the group with a higher probability of being infected) will invest more in education and will have more children. The predictions of the model are illustrated using some results of the literature and stylized facts collected at the family level at baseline.

The paper is organized as follows. Section 2 describes the historical difference between sympatric ethnic groups in Mali and gives previous evidence on the links between malaria, cognition and education. We analyse the effect of malaria on education in section 3 . We discuss the economic implications of this result in section 4. Finally, Section 5 summarizes and discusses implications of the results.

\section{Background evidence}

\subsection{Differential malaria prevalence amongst sympatric ethnic groups in Mali}

Malaria is one of the most serious public health problems in Mali. It accounts for 37.5\% of health clinic consultations and $72 \%$ of deaths amongst children under 5 years old, and is the main cause of anaemia amongst pregnant women (Système Local d'Information Sanitaire 
or SLIS, 2007). Immunity to malaria is dependent on both the innate and the adaptive arms (both cell- and antibody-mediated) of the immune system, which are required for adequate protection. Previous studies have shown that the Fulani children have a stronger inflammatory and antibody responses against malaria parasites compared to the Dogon, and that these differences are already evident at an early age, therefore probably depending on the innate arm.

The Fulani traditionally were nomadic pastoral people and have now settled in various parts of the African continent. One such site of settlement is northern Mali where they have lived for at least 200 years. The Dogon, on the other hand, are farmers that migrated to the study area of northern Mali about 500 years ago. The inhabitants of the Fulani and the Dogon villages in this area do not inter-marry and are therefore considered sympatric ethnic groups. The Dogon population constitutes the majority in this area, but other marginal ethnic groups (the Malinke, Bambara, Bobo and Mossi) also live in the study area. We thus refer to the Dogon ethnic group and other minority groups as the "Non-Fulani" ethnic group. However, we also perform specific analysis using the Dogon group alone (referred to as the "Dogon only" ethnic group).

When assessing malaria parasite rate, parasite density and malaria-specific antibodies of several sympatric ethnic groups in West Africa, inter-ethnic differences were found (Modiano et al., 1995). The Fulani were less infected and had lower parasitemia than other ethnic groups. Findings from Modiano et al. (1995) suggest that the Fulani were more resistant to malaria. Further studies from Sudan showed consistent inter-ethnic differences in malaria infection rates, malaria morbidity, prevalence and levels of anti-malarial antibodies (the Fulani also inhabit Sudan) (Nasr et al., 2009). The Fulani were again less infected by parasites, less affected by the infection and more responsive to the antigens tested. These differences could not be explained by the use of malarial protective measures such as bednets, various other protective measures, or exposure to infective bites, nor did socio-cultural or environmental factors seem to play a role in the relatively better protection against malaria seen amongst the Fulani. In addition, the Fulani did not show higher frequencies of known genetic factors of malaria resistance (Modiano et al., 1995, 2001).

When studying differences in susceptibility to malaria between two sympatric ethnic groups in Mali (see for instance (Dolo et al., 2005)), it was shown that the Fulani had higher 
spleen enlargement rates $^{5}$, lower parasite density and were less affected by malaria than the Dogon group. The Fulani also had higher titers of antimalarial antibodies than the Dogon group (Dolo et al., 2005) which means that they had stronger immune responses.

In other previous studies, inter-ethnic differences were observed in some cytokines. Cytokines and chemokines are essential mediators during malaria infection, and the balance between pro- and anti-inflammatory cytokines may be important for the clinical outcome of malaria responses amongst the Dogon (Arama et al., 2011).

Attempts to link this relatively better protection during malaria infection seen among the Fulani to different polymorphisms in candidate genes have so far not given a satisfying explanation of the underlying cause of the protection, and the more pro-inflammatory response seen in the Fulani but not in other sympatric ethnic groups: they could not provide a convincing explanation of the relatively better protection against malaria seen among the Fulani (Driss et al., 2011). Put differently, genetic factors - usually associated with malaria protection and common to different populations - do not seem to be the key explanatory variables of this protection. Epigenetic studies ${ }^{6}$ could help understanding what regulates these differences, but research has not yet reached this stage.

\subsection{Previous evidence on malaria, cognition and education}

Malaria can impact children's educational achievement through a number of ways. First, malaria during pregnancy can lead to foetal growth retardation, which translates into cognitive and physical impairments among children. Barreca (2010) analyzes the long-term impact of in utero and post-natal exposure to malaria. He finds that such exposure leads to considerably lower levels of educational attainment, and higher rates of poverty later in life.

Second, during early childhood (under the age of five), complicated forms of malaria may develop rapidly. Indeed, acquired immunity in children does not play an efficient protective role until the ages of 5 to 6 years old, even in highly endemic areas. This highlights the

\footnotetext{
${ }^{5}$ Splenomegaly is an enlargement of the spleen resulting from an abnormal immune response to repeated attacks of malaria. Many of the mechanisms leading to an enlarged spleen are exaggerated forms of normal spleen function, and a wide variety of diseases (schistosomiasis, post-necrotic cirrhosis, thalassemia, leukemia, lymphoma, myelofibrosi) are associated with enlargement of the spleen. The role of the spleen during malaria in humans remains unclear.

${ }^{6}$ Epigenetics is the study of inherited changes in phenotype or gene expression caused by mechanisms other than changes in the underlying DNA sequence (Bird, 2007).
} 
reason why malaria continues to be a major threat to child survival. The effects of severe malaria, better known as cerebral malaria, have been quantified by numerous studies ${ }^{7}$. For instance, Ngoungou et al. (2007) provide a quantification of the burden on educational achievement in West Africa. In their study, 101 subjects (mean age of $5.6 \pm 3.6$ years) who had had cerebral malaria in Mali were followed from 1999 to 2001. The authors found that 28 children exhibited persistent neurological sequelae (26.7 \%). Among them, eight (7.9 \%) children had developed these sequelae just after cerebral malaria, and $20(19.8 \%)$ a few months later. These sequelae included headaches, mental retardation, speech delay, bucco-facial dyspraxia, diplegia and frontal syndrome (one case each), dystonia (two cases), epilepsy (five cases), as well as behaviour and attention disorders (15 cases).

Third, even during late childhood, which usually extends from 6 to 16 years of age, the protection conferred by acquired immunity is only partial. If cerebral malaria is rare at this stage, "simpler" cases of clinical malaria (called "uncomplicated malaria"), in addition to repeated illness or chronic malaria infections, are not. They can have a non-cognitive impact on educational achievement through school absenteeism, general health conditions, and investment in curative strategies (coping strategies against the disease detrimental to educational investments). For instance in a Kenyan case study, Brooker et al. (2000) attribute $13 \%$ to $50 \%$ of medically-related school absences to malaria. In Kenya, primary school students were found to miss $11 \%$ of the school year (20 school days missed per child-year). In Nigeria, school days missed varied between $2 \%$ to $6 \%$ of the school year (3 to 12 days per year per student). In the specific case of Mali, malaria was the primary cause of absenteeism during the full school year (Thuilliez et al., 2010). Moreover, although the age distribution of uncomplicated malaria and asymptomatic malaria depends on transmission intensity, the total burden of the disease may be similar or even higher in settings of low transmission due to patterns of acquired immunity. Malaria morbidity among school-age children increases as transmission intensity decreases, but asymptomatic infections are more frequent in high transmission settings (Clarke et al., 2004).

Fernando et al. (2003) show that there exists a significant negative correlation between the total number of malarial attacks experienced by children and test scores during a six year follow-up. Fernando et al. (2006) and Jukes et al. (2006) also show a substantial effect of pre-

\footnotetext{
${ }^{7}$ Refer to Mung'ala-Odera, Snow and Newton (2004) for a literature review.
} 
ventive treatment in two randomized studies. Despite these results, however, asymptomatic malaria specifically has proven to have detrimental effects on children's cognitive and educational skills in three studies, one being a cluster-randomized control trial which suggests either a direct effect of the disease or an antimalarial treatment effect (Clarke et al., 2008; Thuilliez et al., 2010; Nankabirwa et al., 2013). The mechanism of this potential causal relationship could include a "toxicity effect, leading to biochemical changes in the central nervous system (CNS); excitation of the immune system, leading to changes in behaviours related to appetite and reaction time; and physiological effects such as discomfort and disturbed sleep,leading to reductions in activity levels or causing behavioural change" (Holding and Snow, 2001).

\section{Short-run impacts of malaria on cognitive test scores and educational performance}

\subsection{Study area and survey methods}

The study took place from early October to early December 2010 in the village of Diankabou in the Mopti area, $850 \mathrm{~km}$ northeast of Mali's capital, Bamako. Malaria is mesoendemic ${ }^{8}$ The entomological inoculation rate ${ }^{9}$ was previously shown to be similar in both ethnic groups under study - the Fulani and the non-Fulani. Transmission is seasonal from July to October every year (Farouk et al., 2005; Dolo et al., 2005; Bereczky et al., 2006; Vafa et al., 2007, 2009). Economic activity has been strongly impacted by tourism over the last two decades since the Dogon Country was listed as part of UNESCO's natural and cultural world heritage in 1989. Moreover, convergence of production systems between the Fulani and other ethnic groups, as a result of farmers engaging in cattle breeding and herdsmen in agriculture, has been documented (Breusers, Nederlof and Van Rheenen, 1998).

The sample design consists of an exhaustive survey of all the children living in Diankabou and enrolled in the school of Diankabou, who accepted to participate in the study. A total

\footnotetext{
${ }^{8}$ Mesoendemic malaria endemicity is defined by a parasite rate $(\mathrm{PR})$ between 0.11 and 0.5 in this area with $P$. falciparum being the main prevalent parasite species.

${ }^{9}$ The "entomological inoculation rate" is the commonly-used measure of the intensity of malaria transmission. EIR is a commonly used metric that estimates the number of bites by infectious mosquitoes per person per unit time (Smith et al., 2007).
} 
of 300 children were enrolled in the village's school in September 2010. Our study includes 296 children at baseline and 291 at endline (5 children were lost at the endline mostly due to absences at the endline $)^{10}$. Data was collected at the beginning of the school year during two cross-sectional surveys, in October 2010 and December 2010. As illustrated by New et al. (2002a), October still corresponds to the malaria season whereas December is not considered anymore a transmission season in this area ${ }^{11}$ Notably, this seasonal change leads to a differential decline in malaria infection in both groups. As it is naturally more susceptible, the non-Fulani group is more affected by this decline.. Once informed consent had been obtained, all participating pupils received clinical and laboratory examinations ${ }^{12}$ during two "active" follow-ups. Tests were administered the same day directly in the school ${ }^{13}$.

The data collected included the children's malaria infection status, measured with high precision through PCR, anthropometrics, cognitive outcomes, and the ethnic group. Definitions and details on the variables are provided in Appendix A.

\subsection{Natural experiment and empirical equation}

In order to provide evidence on the effects of malaria on educational outcomes, we use a quasi-experimental approach in which we exploit ethnic variations across individuals of the two sympatric ethnic groups, and the natural variation of malaria intensity in the village (at the end of the malaria transmission season which fixes our before/after framework). Two factors combine to determine the identification strategy of this first part: (i) the exogenous origin of change in malaria exposure (pre- and post-seasonal change); (ii) the use of the Fulani ethnic group for comparison (the Fulani are less susceptible and provide a good counterfactual).

\footnotetext{
${ }^{10}$ Note that we also have a limited number of missing values for some of the variables under study here due to the difficulties inherent in biomedical data collection and storage in remote areas, refusals to conform to particular procedures or to perform some tests.

${ }^{11}$ Malaria transmission in this area increases from July to October. It then declines during the other months of year. New et al. (2002a) show similar seasonal trends from 1960 to 1990, and epidemiological studies in this area confirm the timing of this seasonal shift (Farouk et al., 2005; Dicko et al., 2005; Dolo et al., 2005; Bereczky et al., 2006; Vafa et al., 2007, 2009).

${ }^{12}$ Clinical refers to the assessment of symptoms while laboratory refers to the biomedical measurement of infections.

${ }^{13}$ The study protocol was approved by the institutional review board (IRB) ethics committee of the National School of Medicine and Pharmacy of Mali. Community and individual written informed consent were obtained before starting the study. Panel data were collected directly in the field by the authors.
} 
To estimate the average treatment effect (ATE), a natural approach is to estimate equation (1):

$$
E_{i t}=\alpha_{0}+\gamma_{1}\left[\text { Post }_{t} \times \text { NonFulani }_{i}\right]+\gamma_{2} \text { Post }_{t}+\omega X_{i t}+F E_{i}+\epsilon_{i t},
$$

where $E$ represents the outcomes of interest here (cognitive or educational outcomes) $)^{14}$, Post is the period of observation (taking a value of 1 for early December (just after the seasonal change), and 0 for early October (just before the seasonal change)). NonFulani is a dummy variable for non-Fulani ethnic groups, whereas $X$ is a set of covariates at individual level that vary across time, including other health covariates (malaria symptoms, splenomegaly, BMI for age $\mathrm{z}$-score, haemoglobin concentration). $F E$ are child fixed effect intended to capture time invariant effects (including ethnicity, educational practice effects), other baseline parasite infections and socioeconomic factors at baseline), and finally $\epsilon$ is an individual-specific error term.

However, the natural immunity of the Fulani (the control group) is not fully protective against the disease and the reduction in malaria infection after the exogenous seasonal change amongst the non-Fulani is not fully efficient to eliminate all infections. It is useful for our approach to think about the infection status with respect to seasonal change.

We have four groups of pupils: (i) those who were infected at baseline and uninfected at endline, (ii) those who were uninfected at baseline and endline, (iii) those uninfected at baseline and infected at endline, (iv) those infected at baseline and endline ${ }^{15}$. Indeed, our control group (Fulani) and treated group (non-Fulani) are a mixture of these four categories and we want to estimate the average treatment for those individuals whose malaria infection and parasite density were affected negatively by seasonal change, knowing that the nonFulani have a higher probability to be affected by this change over the three months of study. Consequently, there is no subpopulation available for whom the probability of treatment is zero. In this case, instead of a simple difference-in-difference analysis, Imbens and Angrist

\footnotetext{
${ }^{14}$ We define cognition as the mental process involved in knowing, learning, and understanding things. The cognitive outcome is more particularly defined as the Raven Progressive Matrices test - a non-verbal assessment comprised of pattern matching exercises that progressively increase in difficulty (Raven, 1984). Educational outcome, or educational achievement, refers to the ability of succeeding in education, as measured here by a synthetic primary educational test score.

${ }^{15}$ These four categories can be defined on the basis of a binary infection status or on the basis of the continuous parasite density. In the last case, the reasoning is made in terms of density increase or decrease instead of binary infection status.
} 
(1994) recommend to use the Local Average Treatment Effect (LATE) approach, based on natural experiments. LATE is the average treatment effect for individuals whose treatment status is influenced by changing an exogenous regressor that satisfies an exclusion restriction.

Therefore, we rely on an instrumental variable strategy, where we instrument for malaria status using the interaction term between Ethnicity and Post with main effects for Ethnicity and Post to rescale the simple difference-in-difference, provided in Table 1, in a within child fixed-effects model, following equations (2) and (3), where equation (3) corresponds to a difference-in-difference design applied to malaria infections. We identify the treatment effect for "compliers", i.e. the average treatment effect for those individuals whose malaria infection and parasite density were negatively affected by the seasonal change (a local average treatment effect, LATE).

$$
E_{i t}=\alpha_{1}+\beta M a l_{i t}+\omega X_{i t}+F E_{i}+\epsilon_{i t}
$$

where $M a l$ is a measure of malaria infection, and $\beta$ is the coefficient of interest. We estimate equation 2 by two-stage least squares (2SLS), using the following first-stage equation:

$$
\text { Mal }_{i t}=\alpha_{2}+\gamma_{1}\left[\text { Post }_{t} \times \text { NonFulani }_{i}\right]+\gamma_{2} \text { Post }_{t}+F E_{i}+\mu_{i t}
$$

where Post is the period of observation (taking a value of 1 for early December (just after the seasonal change), and 0 for early October (just before the seasonal change)), NonFulani is a dummy variable for non-Fulani ethnic groups, and $F E$ is a child fixed - effect intended to capture time invariant effects (including ethnicity).

The identifying assumption is that there are no unobserved factors directly affecting the outcomes that (i) are correlated with seasonal change and (ii) are correlated with ethnic specific malaria infectious status. To our knowledge, there is no evidence that ethnic differences, a marker of risk for malaria infection, plays any role in the education production function. There is also no reason to believe that ethnic differences per se should play any role in this function. In addition, there is no reason that the difference in performance between infected and uninfected individuals shoulGrant DU 283953),d be smaller during the low malaria season than during the high malaria season. As a consequence, the main strong assumption is that the seasonal changes in outcomes between the two groups can only be attributable 
to malaria. Note that malaria transmission decline does not fit exactly with agricultural activities in this area. As shown by Figure A1, average precipitations in Diankabou are declining between September and October whereas the highest drop in malaria transmission takes place in November in this area (Coulibaly et al., 2013). However a number of threats to inference in the LATE design can still jeopardise our results. We discuss theses issues in greater detail in section 3.5. The identifying assumption is that there are no unobserved factors directly affecting the outcomes that (i) are correlated with seasonal change and (ii) are correlated with ethnic specific malaria infectious status. To our knowledge, there is no evidence that ethnic differences, a marker of risk for malaria infection, plays any role in the education production function. There is also no reason to believe that ethnic differences per se should play any role in this function. In addition, there is no reason that the difference in performance between infected and uninfected individuals should be smaller during the low malaria season than during the high malaria season. As a consequence, the main strong assumption is that the seasonal changes in outcomes between the two groups can only be attributable to malaria. Note that malaria transmission decline does not fit exactly with agricultural activities in this area. As shown by Figure A1, average precipitations in Diankabou are declining between September and October whereas the highest drop in malaria transmission takes place in November in this area (Coulibaly et al., 2013). However a number of threats to inference in the LATE design can still jeopardise our results. We discuss theses issues in greater detail in section 3.5.

\subsection{Descriptive statistics and simple difference-in-difference}

The results from the simple difference-in-difference approach are provided in Table 1 and A1. Table 1 provides the results of the descriptive analysis for selected variables but does not rescale the difference-in-difference based on the differential change in infection rates across ethnic groups. Our results are similar to various other research findings from other villages located in the same area. Comparing the two groups, the Fulani were less affected by malaria than the Non-Fulani, as expected. For instance, in November 1998 and November 1999 (corresponding approximately to our baseline survey made at the end of rainy season), in the same area and with a similar sample size, Dolo et al. (2005) find a parasite prevalence difference of $15.6 \%$ and $13 \%$ respectively $(P$-values $<0.001)$. We find a $19.2 \%(P$-values $<0.001)$ 
difference in October 2010. Moreover, at the very end of the dry season in July 2004, they find a parasite prevalence difference of $-2.2 \%(P$-value $=0.220)$ between the Non-Fulani and the Fulani. We find a non-significant difference of $-0.015 \%(P$-value $=0.825)$ in December 2010, at the beginning of the dry season. The same was observed for malaria symptoms in our data and across research papers: the Fulani ethnic group has fewer clinical symptoms. By contrast spleen enlargements, lower nutritional status and anaemia were more prevalent within Fulani children, still in accordance with the literature on this topic (Dolo et al., 2012a). However, all educational and cognitive test results were not statistically different between the two groups and no other factors (except age at the baseline, P-values $<0.100$ ) differed across groups. The prevalence of other parasite infections (urinary schistosoma and intestinal parasites) was similar in the two groups at the baseline.

Amongst the non-Fulani ethnic group, the parasite rate fell from $87.1 \%$ to $25 \%$ (i.e. a 62 percentage point decline) between October and December 2010. Amongst the Fulani ethnic group, the parasite rate fell from $67.9 \%$ to $23.5 \%$ (i.e. a 44.4 percentage point decline). The decline was thus large. The last column presents the OLS regression results (standard errors are clustered at the family level) from a simple difference-in-difference analysis. The decline in malaria exhibited significant variation across ethnic groups (17.8 percentage point differential decline between the non-Fulani and the Fulani). ${ }^{16}$ The only other differential changes observed across time are malaria - related symptoms (cephalgia and vomiting decreased more amongst the non-Fulani ethnic group) whereas haemoglobin concentration increased significantly more amongst the non-Fulani. Notably, the last column of Table 1 shows no significant effect of the interaction term $\left(\right.$ Post $_{t} \times$ NonFulani $\left._{i}\right)$ on cognition and education. Table A1 provides additional results and shows no significant effect of the interaction term $\left(\right.$ Post $_{t} \times$ NonFulani $\left._{i}\right)$ on cognition and education.

\section{Table 1 about here.}

\footnotetext{
${ }^{16}$ Note that similar results are found with the Dogon "alone" ethnic group instead of the non-Fulani category.
} 


\subsection{Results}

Table 2 presents the regression results on the effects of malaria on cognitive and educational outcomes, using the LATE approach. Column (1) presents the coefficients from the OLS estimation of equation 2 (not equation 1). All other columns provide the coefficients from the 2SLS estimates. Robust standard errors are clustered at the family level. The within-child fixed-effects results are given in columns (5) and $(6)^{17}$. The low $p$-values from the DurbinWu-Hausman test indicate that malaria infections should be treated as endogenous. Note that PCR detects very low parasite loads, which is useful to detect diagnose asymptomatic malaria, knowing that symptomatic aspects are just the tip of the iceberg. However the PCR technique used here only provides us a dummy variable for cases tested positive for malaria. As an alternative measure of malaria infection we also use malaria positive cases detected through microscopy and the parasite loads measured by microscopy. Microscopybased parasite density, though less sensible and sensitive than PCR, enables us to rely on a continuous variable, and thus much more variation. The results are provided in Table A2. Column (1) from this table shows that the microscopy measures suffer from measurement error.

\section{Table 2 about here.}

The results show significant negative effects of malaria infection on cognitive and educational outcomes. The regressions with controls include all malaria symptoms provided in Table 1 (five dummies for fever, cephalgia, vomiting, diarrhea, and abdominal pain), in addition to health status characteristics (splenomegaly, BMI-for-age, haemoglobin concentration). Notably, the coefficients of interest do not change significantly as fixed effects and control variables are added to the specifications, thus providing some validation to the identification strategy. More particularly, adding symptom controls does not change the size of the coefficients, suggesting an effect of the presence of the parasite per se. When reducing the sample size to the Fulani and "Dogon alone" ethnic groups, the sample size is reduced by 28 to 30 observations, but the results remain unchanged.

To put this in context, the estimates imply that a malaria infection increase resulted in a decrease in the cognition score of 0.887 , a decrease in PCA score of 1.157 and a decrease

\footnotetext{
${ }^{17}$ Note that the $F$-statistics mitigate "weak instrument" concerns.
} 
in educational average score of 0.424 (Table 2, column 5). Since the range of these variables respectively are $[-2.217 ; 3.832],[-3.780 ; 4.631]$ and $[-1.884 ; 1.978]$, the magnitudes of the coefficients imply that being infected by malaria decreases the cognition score by 0.89 standard deviation, decreases the PCA educational score by 0.84 standard deviation and decreases the average educational score by 0.648 standard deviation. The latter suggests that results are also robust across educational outcomes. Table 3 provides the first - stage estimates. We show the results of a linear probability model where we regress a dummy variable equal to one if the child was infected on ethnicity, the period of observation and the interaction term.

\section{Table 3 about here.}

To further understand the mechanisms through which malaria might affect cognition and education, table 4 reports estimates for competing channels (haemoglobin levels and having at least one malaria symptom). One hypothesis suggested in the medical literature on the effects of malaria on cognition and education is through decreases in haemoglobin concentrations. Clinical longitudinal follow-up data showed that the Fulani children have lower hemoglobin levels than Dogon children (Dolo et al., 2012b). Put differently, the Fulani suffer more from anaemia than the Dogon, despite their lower susceptibility to malaria ${ }^{18}$. We could also expect a greater effect of malaria symptoms on cognition and education compared to parasite infections. Malaria infection could thus have both a direct effect on education and an indirect effect through symptoms. The direct mechanism could include a "toxicity effect," ${ }^{19}$ leading to biochemical changes in the central nervous system (Holding and Snow, 2001). Moreover, if malaria infection had a direct impact on symptoms but no direct impact on cognition and education, the PCR measure could just be a proxy for symptomatic infections. This does not seem to be the case.

The coefficients of interest do not change significantly when new channels are added and instrumented. In addition, none of the variables tested in these tables and instrumented with the same procedure (haemoglobin levels and having at least one malaria symptom) seem to have an impact on education.

\footnotetext{
${ }^{18}$ Malaria is a major cause of anaemia (Kurtzhals et al., 1999).

${ }^{19}$ Toxicity involves harmful effects in the brain through a single or short-term exposure.
} 
However, there could be a two-fold penalty here, as the presence of malaria parasites had a direct effect on the educational achievement and cognitive performance, but symptoms also have a negative impact on education (Fernando et al., 2003). The number of symptomatic cases was rather limited during the two "active follow-ups" (as opposed to continuous clinical case detection or clinical consultations), in accordance with previous studies (Dicko et al., 2005). This fact may explain why we do not find any effects on symptoms here.

Acute cases of illness (of any type) were treated immediately and monitored by the medical team directly in the field. This could bias our estimates of the treatment effect. Nonetheless, for the specific cases of malaria, it is important to highlight that even after receiving an antimalarial treatment, patients can still be at risk of treatment failure in the short-term (within 14 days), of late recrudescence (28 days) and of re-infection with new parasite strains. Indeed, after a treatment, a period of 14 days is generally used for considering a second malaria infection as a new case (Dorsey et al., 2002). Consequently, as there were more than 14 days between the baseline (October) and the endline (December), infections at the endline can be considered as new cases. However, we test the robustness of our results by including treatments in our regression models. The results are provided in Table 4 and do not change our main conclusions. The following section discusses systematically the potential threats to the estimation strategy and provides a series of robustness tests.

\section{Table 4 about here.}

\subsection{Potential threats to validity}

The first among threats to the validity of our research is related to ethnic-specific elasticities of cognition and education with respect to health. One concern is that the responsiveness of education to health improvements might differ by ethnic group. As suggested by Jayachandran and Lleras-Muney (2009) for gender, if a given improvement in health has a larger effect on the education of the Fulani than the non-Fulani, then our results could be driven the differential sensitivity to this health improvement between the ethnicities, not by the differentially larger improvement in health for the non-Fulani due to seasonal change. This differing elasticity to health improvements by ethnic group could operate through morbidity affecting absences or improvements in family members' health. We tested for ethnic-specific 
cognitive or educational effects of other health improvements that were common to the Fulani and the non-Fulani (such as BMI-for-age z-scores) in Table 5. There is no strong evidence for a greater elasticity of the non-Fulani or the "Dogon alone" as the results do not change our main conclusions.

Second, pre-existing endowment differences could also drive the results. For instance, if the non-Fulani are drawn from the sicker part of the distribution, then one might retrieve similar results. This could be particularly true for aneamia and splenomegaly, which could reflect differences in other investments made in the Fulani children that have a seasonal pattern. Indeed, anaemia is a marker of malaria severity but is also driven by other factors (nutritional intake for instance). Appendix Figures A2 to A6 provide densities of hemoglobin concentrations, splenomegaly, BMI-for-age, cognition and education variables. These figures show that the anaemia level is relatively high on average for both ethnic groups and there is no evidence that the non-Fulani are drawn from the sicker part of the distribution. We note that the prevalence of anaemia among school-age children is generally defined as a hemoglobin concentration of less than $11.0 \mathrm{~g} / \mathrm{dL}$. Similarly the distributions of splenomegaly, BMI-for-age, cognitive or educational outcomes do not show major differences across ethnic groups. In order to confirm that differences in baseline health do not affect our results, Table A3 provides estimates by interacting malaria infections with baseline anaemia - as defined by the previous threshold - and with baseline splenomegaly to estimate the effects on cognitive and educational outcomes. Table A3 also analyzes the question of cross-group spillovers (e.g., malaria among non-Fulani children could impact learning among Fulani either positively or negatively due to classroom effects) by interacting classrooms with malaria. Therefore our results do not seem to be influenced by potential heterogeneity.

The third potential threat to validity relates to cross-seasonal behavior that reinforces or compensates investments in education, which could differ by ethnic group or to their differential access to health care across seasons. Though we have limited information about ethnic-specific activities across seasons in Diankabou, as the time frame of the survey was limited, we did check in the Mali Demographic and Health Survey (DHS) collected from 2001, 2006 and 2012-2013 in rural areas of the Mopti region across different months (couple recode) that there are no particular cross-seasonal ethnic-specific differences (Figure A7 and A8) based on the month of interview. We do not find any significant difference across 
groups and seasons for the wealth index distribution or bednet ownership. Moreover, malaria transmission decline does not fit exactly with agricultural activities in the village. As shown by Figure A1, average precipitations in Diankabou are declining between September and October whereas malaria transmission declines between October and November in this area. In the same area, Coulibaly et al. (2013) have shown similar patterns. The first malaria clinical episodes had a lag of four weeks after the onset of the rainy season (from June to October). The main decline in malaria incidence in this area occurs generally in November.

Moreover, we also provide a robustness test of our results in another context that involves the Fulani ethnic group by using data from another village in Mali. This village, Donéguébougou, is a small village located in a malaria-endemic area near Bamako $(17 \mathrm{~km}$, North of Bamako) providing free access to health care to all villagers. However, it is not a place where the Fulanis settled in the past and thus their representation is very low, which is the reason why we did not use it in the main analysis. Details about this second village and the survey procedure - that is similar to the one used in Diankabou - can be found in (Thuilliez et al., 2010). A total of 12 Fulani children were surveyed across 8 follow-ups compared to 213 non-Fulanis across 8 follow-ups from November 2007 to June 2008 (hence with much more seasonal variation). Still, this different village provides a useful test of our LATE approach because it provides a distinct set of cultural characteristics. For a start, the non-Fulani ethnic groups are different and are represented by the Sarakole and Bambara. Second, economic and agricultural activities are different in this area as the climate is slightly different. Finally, there was no attrition in this village among the Fulani ethnic group leading to a total of 96 Fulani observations. The results, provided in Table A4, are similar to the ones found in Diankabou.

Another concern is that Diankabou is a remote village $(65 \mathrm{~km}$ from the nearest city and $850 \mathrm{~km}$ northeast of Bamako, the capital of Mali) with difficult field work conditions. No research programs were undertaken previously in this village to our knowledge. Therefore, we face a number of missing values for some of the variables under study here due to the difficulties inherent in the biomedical data collection and storage in remote areas, and refusals to conform to particular procedures or to perform some tests. For instance, the data on cognition comprises 550 observations instead of 587 (data are missing for $6 \%$ of observations) and there are 583 observations for the educational average score (data are missing for 0.6\% 
of observations) and 503 for the PCA score (data are missing for $14 \%$ of observations). Although we cannot directly rule out this concern, sample size variation across variables does not change the conclusions. In addition, restricting the non-Fulani sample to the Dogon ethnic group alone (and thus changing the sample size) does not affect our results. As yet another additional check, we coded all the missing educational outcomes for the Fulani at the maximum value of the outcome in the post period and all the missing educational outcomes for the Non-Fulani at the minimum value of the outcome. The results provided in Table 5 are robust to this check.

Finally, considering the very short time period of the study and the limited size of the village, it is highly improbable that the village of Diankabou underwent major changes during the study period, such as unobserved education-related changes. The identification would have been threatened if changes had ethnic-specific effects that varied by individual in a manner correlated with the malaria seasonal changes. We are not aware of any major ethnic-

specific changes between October and December, apart from the potential ones discussed above.

The discussion section below provides other arguments on long-term potential compensating mechanisms that differ by ethnic group and could explain the observed difference between Table 1 and Table 2. We notice that the conclusion of our empirical test confirms other research papers (Clarke et al., 2008; Thuilliez et al., 2010; Nankabirwa et al., 2013) on the effect of malaria on education, as applied to the two ethnic groups. In addition, as malaria is endemic in this area, the short term effect of malaria on educational and cognitive outcomes is potentially permanent in this area, as far as malaria has not been eliminated.

\section{Table 5 about here.}

\section{Discussion}

In the previous Section, we have shown that malaria decreases the return to educational investment. It has an impact on cognitive test scores and educational performance. Nevertheless, Table 1 has shown that the non-Fulanis do not outperform the Fulanis at the baseline or the endline separately. Moreover, the simple difference-in-difference estimates 
provided in Table 1 and A1 show no significant difference between both groups. This suggest that malaria has a short-run impact and that catch-up effects may take place. Indeed, although malaria is endemic in the village, i.e. transmitted all over the year, its intensity of transmission varies with the seasons.

In order to provide a discussion on the possible long-run implications of short-run impacts of malaria on educational performance, we build a model characterizing economic and fertility decisions within the household. The theoretical predictions are then illustrated by utilizing some stylized facts collected at the family level at the baseline, in addition to some facts from the Mali Demographic and Health Surveys (from 2001 to 2013) and the literature on the topic. An extensive test of the predictions of our model is beyond the scope of this paper as our data do not permit it.

We consider a quantity-quality model, in which parents choose their fertility and their investment in the education of their surviving children, and apply it to the case of a differential susceptibility to malaria. The probability to be infected (i.e. the infection rate), denoted $p$ with $p \in(0,1)$, is exogenous and varies across ethnic groups.

Malaria has two impacts. First, it increases the child mortality rate, which is a wellestablished fact (Murray et al., 2012). We define a survival function that measures the probability of reaching schooling age, and assume it decreases with the infection rate of the considered ethnic group. The survival function is denoted $s(p)$ and satisfies $0<s(p)<1$ and $s^{\prime}(p)<0$. We denote the fertility rate by $n$ and therefore consider that $s(p) n$ is the number of children that reach schooling age in the considered household. We notice that according to the model, malaria has no impact on adult longevity. The second impact of malaria is to reduce educational outcomes (which is the result obtained in section (3). We denote by $e$ the monetary cost of education per child made by the parents. We then assume that returns to education are equal to $R e$ provided that the child has been ill and to $\delta R e$ otherwise. We consider in the model that $\delta \geq 1$, which allows us to distinguish two cases: $\delta=1$ means that malaria has no impact on educational outcomes, whereas $\delta>1$ implies that children who were ill exhibit lower outcomes (which is the result of Section 3).

Parents share their income, denoted $w$, between consumption, $c$, and the costs of their surviving children:

$$
w=c+(e+\lambda) s(p) n
$$


where $\lambda \geq 0$ accounts for fixed costs per child. The expected utility of the parents depends on consumption, net fertility and returns to education. It can be written as:

$$
u(c)+s(p) n[p v(R e)+(1-p) v(\delta R e)]
$$

where functions $u$ and $v$ are increasing and strictly concave and $v(0)=0$. We notice that considering the utility of expected returns rather than (5) would not affect the results presented below. The optimization problem of the parents is to choose $(c, n, e)$ that maximize (5) subject to (4). We assume that solutions are interior and denote them by $\left(c^{*}, n^{*}, e^{*}\right)$. They satisfy two first-order conditions where $e^{*}$ is such that the marginal utility of consumption is equal to the expected marginal utility of education and that $n^{*}$ is such that the marginal utility of consumption is equal to the "return" of one additional surviving child; a "return" that is given by the ratio of the expected utility of education over the cost $(e+\lambda)$. Using those conditions, we derive below some theoretical relationships between the exogenous parameters and the optimal pair $\left(e^{*}, n^{*}\right)$. Below are the predictions of the model concerning the education choices.

Proposition 1. The optimal investment in education $e^{*}$,

i) does not depend on parental income w,

ii) increases with the infection rate $p$ provided that the relative risk aversion is constant or increasing and that $\delta>1$.

Proof. See Appendix B.

By combining the first-order conditions of the problem, the expected marginal utility of education should equal the "return" of one surviving child. This relationship gives the optimal investment in education, which therefore does not depend on parental income. The main result of Proposition 1 is to exhibit a condition such that the relationship between infection rates and investment in education is positive. This relationship, however, is $a$ priori ambiguous as the "return" of a child's education decreases with $p$ while the expected marginal utility of education increases with $p$. If the relative risk aversion is increasing or constant (which is empirically evident in Holt and Laury (2002) and Chiappori and Paiella (2011)), the second effect would dominate the first. Hence, parents compensate a lower expected return to education by making a larger investment. We notice that our result still 
holds if the relative risk aversion is decreasing, provided that the fixed cost of each child is not too large, which is also generally considered to be the case in rural Africa, and more notably when considering the high opportunity cost of schooling (Estevan and Baland, 2007; Bargain, Donni and Kwenda, 2011; Dunbar, Lewbel and Pendakur, 2013).

The theoretical result of Proposition 1 might be surprising. One would expect that a decrease in the return to education would lower the investment in education (see, most notably, the nice presentation by Bleakley (2010a)). Nevertheless, as argued by Soares (2005) and Hazan and Zoabi (2006), the quantity-quality trade-off challenges this intuition as changes in morbidity also influence the return of educational investment on the quantity of children.

To discuss the empirical relevance of Proposition 1 we recall that $\delta>1$ is the main result we presented in section 3. Let us now establish some stylized facts to illustrate the sign of the theoretical relationships. Table 6 uses data collected at the family level in October 2010 during the baseline survey to illustrate this proposition. In particular, Column (1) shows that investments in education do not depend on parental income, and that they increase with the probability of being infected.

We now turn to the predictions of the model concerning the fertility choices.

Proposition 2. The optimal fertility, $n^{*}$,

i) increases with parental income $w$,

ii) increases with the probability to be infected, $p$, if $\delta$ is not too large.

Proof. See Appendix B

The relationship between fertility and the infection rate depends on two factors. First, as malaria negatively impacts the survival rate of infants, the infection rate tends to increase fertility trough a compensation effect. Second, as we have seen in Proposition 1, the infection rate may increase investments in education, which in turn decreases fertility through a quantity-quality trade-off. Proposition 2 says that if the second effect is not too strong (i.e. if the relative advantage of healthy pupils measured by $\delta-1$ is not too large), the first effect dominates.

This condition fits well with the estimates we presented in Section 3 where we showed that $\delta$ is significant but not too large (less than one standard deviation for all outcomes). Before 
illustrating Proposition 2, we note that the evidence on the relationship between malaria and fertility is mixed. Using data from the 1961 Italian census when malaria was endemic in Sardinia, Zei, Lisa and Astolfi (1990), Lisa et al. (1994) and Astolfi et al. (1999) observed differential fertility between women living in areas with differing degrees of malaria infection. In fact, a positive relationship was found between fertility and malaria transmission. The average number of live-born children was invariably higher in the areas with the highest malaria risk, after controlling for socio-cultural factors. Conversely, Lucas (2013) showed that the national malaria eradication campaign in Sri Lanka raised fertility. In Africa, however, there is no clear evidence of this relationship. Several studies,for instance reported lower fertility among the Fulani. Furthermore, the observed differential fertility among the Fulani and the non-Fulani has been observed in different cultural contexts (David and Voas, 1981; Hill and Thiam, 1987; Hampshire and Randall, 2000). However, as the discovery of a lower susceptibility of the Fulani group to malaria infections is relatively recent, the role played by malaria in this process has not been deeply explored yet.

Column (2) of Table 6 shows that the total number of children per family in one household increases with parental income and with the probability of being infected (as measured by ethnicity). Column (3), on the other hand, illustrates Proposition 2 with the Mali Demographic and Health Survey (DHS) collected in 2001, 2006 and 2012-2013 in rural areas of the Mopti region. Recall that our study takes place in this area and that the different ethnic group live in sympatry within this area, which is not the case elsewhere in Mali.

We use the couple data, which has one record for every couple. It contains data for men and women who are married or living together and who both declared to be living together. The statistical unit of analysis in this file is the couple for which both partners were interviewed. We use the DHS wealth index as a measure of long-term income constructed with household assets. Regression (3) shows similar results as those seen before. The total number of children ever born per family increases with parental income and increases with the probability to be infected (as measured by the non-Fulani variable).

Unfortunately, DHS does not provide educational investment to test Proposition 1 on a larger dataset. Testing external validity of these results in a larger area and analyzing catchup effects of the non-Fulani ethnic group in the long-run, constitute important avenues for further research. 


\section{Table 6 about here.}

\section{Conclusions}

Our empirical results suggest that malaria infection (as measured by PCR) has a direct impact on cognitive and educational outcomes. These results are also robust to including a number of control variables and to a series of tests. We use a natural experiment which differs from a randomized control trial.

Although an extensive biomedical literature analyzes the costs of immunity, the social costs of immunity have not yet been explored. The findings of the model proposed in the discussion section suggest that, for the ethnic groups under study here, a higher probability to be infected by malaria might increase fertility and human capital investments. On the other hand, the survival of those groups that are partially immunized against malaria might be threatened. Indeed and interestingly, despite having lower malaria-specific mortality rates, the survival of the Fulani ethnic group will depend on fertility decision when they live in sympatry with other ethnic groups. This is certainly not a negligible consequence of immunity, from an economic evolution perspective. Notably, the model converges with observed unexplained fertility behaviors of the Fulani in different contexts and with our aggregate data. Therefore, though stylized, this discussion could be highly relevant for the further development of these issues in the future.

Our article also emphasizes coping mechanisms and catch-up effects that may be at play in the long-run across ethnic groups. Indeed the seasonal shock under study here is only a temporary shock that does not affect the probability of being infected by ethnic group in the long run or the average probability of being infected over a full year of schooling. Moreover, this seasonal change is an imperfect treatment to eliminate malaria amongst all ethnic groups. The originality of our results lies in that they go beyond the findings of the above-mentioned previous studies on income or human capital accumulation and we emphasize potential coping mechanisms that can cause the estimation of that effect to be biased or difficult to assess with a simple difference-in-difference framework. We emphasize the potential changing behavior of those households that have a lower probability of infection because of natural protection against the disease. This is particularly important, considering 
malaria-selective pressure on the human genome.

The findings of this paper also suggest that the increase in human capital accumulation that results from malaria decrease is an important component of malaria control policies and cost-benefit analyses of malaria control programmes. First, protective factors against malaria might be taken into account in defining the target population of malaria control programmes to avoid disadvantaging specific groups. This could be particularly relevant for Glucose-6phosphate dehydrogenase deficiency (G6PD deficiency) in Africa. Carriers of the G6PD allele appear to be protected to some extent against malaria. Hight median prevalence of G6PD deficiency (peaking at 32.5\%) was predicted across sub-Saharan Africa (Howes et al., 2012). Second, testing the relative impacts of malaria, nutritional status and hemoglobin levels on education is necessary in defining health policy priorities. Our analysis suggests that for school-age children, malaria might be a priority compared to other health problems. However, proper nutrition, especially from conception to age two, along with early childhood stimulation play a critical role in the process of brain formation and development. Low levels of child development are associated with lower school participation and worse performance, and increased reliance on health care, potentially perpetuating inter-generational poverty cycles. Therefore, the timing of interventions is probably crucial here. 


\section{References}

Anchinmane, Vyankatesh T., and Rakesh T. Shedge. 2011. "A Review of Malaria Diagnostic Tools: Microscopy and Rapid Diagnostic Test." Asian Journal of Medical Sciences, 1(2): 75-79.

Arama, Charles, Pablo Giusti, Boström Stéphanie, Dara Victor, Traore Boubacar, Dolo Amagana, Doumbo Ogobara, Varani Stefania, and TroyeBlomberg Marita. 2011. "Interethnic differences in antigen-presenting cell activation and TLR responses in Malian children during Plasmodium falciparum malaria." PloS One, 6(3): e18319.

Astolfi, P., A. Lisa, A. Degioanni, A. Tagarelli, and G. Zei. 1999. "Past malaria, thalassemia and woman fertility in southern Italy." Annals of Human Biology, 26(2): 163173.

Bargain, Olivier, Olivier Donni, and Prudence Kwenda. 2011. "Intrahousehold distribution and child poverty: Theory and evidence from Côte d'Ivoire." Discussion Paper series, Forschungsinstitut zur Zukunft der Arbeit.

Barofsky, Jeremy, Tobenna D. Anekwe, and Claire Chase. 2015. "Malaria eradication and economic outcomes in sub-Saharan Africa: Evidence from Uganda." Journal of Health Economics, 44: 118-136.

Barreca, Alan I. 2010. "The long-term economic impact of in utero and postnatal exposure to malaria." Journal of Human Resources, 45(4): 865-892.

Bartlett, Maurice S. 1937. "The statistical conception of mental factors." British Journal of Psychology. General Section, 28(1): 97-104.

Baudin, Thomas. 2012. "The Optimal Trade-Off Between Quality and Quantity with Unknown Number of Survivors." Mathematical Population Studies, 19(2): 94-113.

Bell, Clive, and Hans Gersbach. 2009. "The macroeconomics of targeting: the case of an enduring epidemic." Journal of Health Economics, 28(1): 54-72. 
Bereczky, S., A. Dolo, B. Maiga, M. Hayano, F. Granath, S. M. Montgomery, M. Daou, C. Arama, M. Troye-Blomberg, O. K. Doumbo, and A. Färnert. 2006. "Spleen enlargement and genetic diversity of Plasmodium falciparum infection in two ethnic groups with different malaria susceptibility in Mali, West Africa." Transactions of the Royal Society of Tropical Medicine and Hygiene, 100(3): 248-257.

Bird, Adrian. 2007. "Perceptions of epigenetics." Nature, 447(7143): 396-398.

Bleakley, Hoyt. 2010a. "Health, human capital, and development." Annual Review of Economics, 2(1): 283-310.

Bleakley, Hoyt. 2010b. "Malaria eradication in the Americas: A retrospective analysis of childhood exposure." American Economic Journal: Applied Economics, 1-45.

Boehm, Ann E. 2001. Boehm Test of Basic Concepts-3: Preschool. San Antonio, TX: The Psychological Corporation.

Breusers, Mark, Suzanne Nederlof, and Teunis Van Rheenen. 1998. "Conflict or symbiosis? Disentangling farmer-herdsman relations: the Mossi and Fulbe of the Central Plateau, Burkina Faso." The Journal of Modern African Studies, 36(03): 357-380.

Brooker, S., H. Guyatt, J. Omumbo, R. Shretta, L. Drake, and J. Ouma. 2000. "Situation Analysis of Malaria in School-aged Children in Kenya-What Can Be Done?" Parasitology Today, 16(5): 183-186.

Cervellati, Matteo, and Uwe Sunde. 2005. "Human capital formation, life expectancy, and the process of development." American Economic Review, 1653-1672.

Chiappori, Pierre-André, and Monica Paiella. 2011. "Relative Risk Aversion Is Constant: Evidence from Panel Data." Journal of the European Economic Association, 9(6): 1021-1052.

Clarke, Siân E., Matthew CH Jukes, J. Kiambo Njagi, Lincoln Khasakhala, Bonnie Cundill, Julius Otido, Christopher Crudder, Benson Estambale, and Simon Brooker. 2008. "Effect of intermittent preventive treatment of malaria on health and education in schoolchildren: a cluster-randomised, double-blind, placebo-controlled trial." The Lancet, 372(9633): 127-138. 
Clarke, Siân E., Simon Brooker, Joseph Kiambo Njagi, Eliud Njau, Benson Estambale, Eric Muchiri, and Pascal Magnussen. 2004. "Malaria Morbidity Among School Children Living in Two Areas of Contrasting Transmission in Western Kenya." The American Journal of Tropical Medicine and Hygiene, 71(6): 732-738.

Coulibaly, Drissa, Stanislas Rebaudet, Mark Travassos, Youssouf Tolo, Matthew Laurens, Abdoulaye K. Kone, Karim Traore, Ando Guindo, Issa Diarra, Amadou Niangaly, Modibo Daou, Ahmadou Dembele, Mody Sissoko, Bourema Kouriba, Nadine Dessay, Jean Gaudart, Renaud Piarroux, Mahamadou A. Thera, Christopher V. Plowe, and Ogobara K. Doumbo. 2013. "Spatio-temporal analysis of malaria within a transmission season in Bandiagara, Mali." Malaria Journal, 12: 82 .

Cutler, David, Winnie Fung, Michael Kremer, Monica Singhal, and Tom Vogl. 2010. "Early-life malaria exposure and adult outcomes: Evidence from malaria eradication in India." American Economic Journal: Applied Economics, 72-94.

David, Nicholas, and David Voas. 1981. "Societal causes of infertility and population decline among the settled Fulani of North Cameroon." Man, 644-664.

Deaton, Angus. 2010. "Instruments, Randomization, and Learning about Development." Journal of Economic Literature, 48(2): 424-455.

Dicko, Alassane, Carsten Mantel, Boureima Kouriba, Issaka Sagara, Mahamadou A. Thera, Seydou Doumbia, Mouctar Diallo, Belco Poudiougou, Mahamadou Diakite, and Ogobara K. Doumbo. 2005. "Season, fever prevalence and pyrogenic threshold for malaria disease definition in an endemic area of Mali." Tropical medicine $\mathcal{E}$ international health, 10(6): 550-556.

Dolo, A., B. Maïga, V. Dara, A. Tapily, Y. Tolo, C. Arama, M. Daou, and O. Doumbo. 2012a. "Place du paludisme dans les syndromes fébriles dans deux groupes ethniques vivant en sympatrie au Mali de 1998 à 2008." Bulletin de la Société de Pathologie Exotique, 105(5): 377-383. 
Dolo, A., B. Maiga, Y. Tolo, A. Tapily, C. Arama, M. Daou, M. Baby, B. Traore, and O. Doumbo. 2012b. "Relation entre l'anémie et le paludisme dans deux groupes ethniques vivant en sympatrie au Mali." Bulletin de la Société de Pathologie Exotique, 105(5): $370-376$.

Dolo, Amagana, David Modiano, Boubacar Maiga, Modibo Daou, Guimogo Dolo, Hamadoun Guindo, Mamadou Ba, Hama Maiga, Drissa Coulibaly, and Hedvig Perlman. 2005. "Difference in susceptibility to malaria between two sympatric ethnic groups in Mali." The American Journal of Tropical Medicine and Hygiene, $72(3): 243-248$.

Dorsey, Grant, Denise Njama, Moses R Kamya, Adithya Cattamanchi, Daniel Kyabayinze, Sarah G Staedke, Anne Gasasira, and Philip J Rosenthal. 2002. "Sulfadoxine/pyrimethamine alone or with amodiaquine or artesunate for treatment of uncomplicated malaria: a longitudinal randomised trial." The Lancet, 360(9350): 20312038.

Driss, Adel, Jacqueline M. Hibbert, Nana O. Wilson, Shareen A. Iqbal, Thomas V. Adamkiewicz, and Jonathan K. Stiles. 2011. "Genetic polymorphisms linked to susceptibility to malaria." Malaria Journal, 10: 271.

Dunbar, Geoffrey R., Arthur Lewbel, and Krishna Pendakur. 2013. "Children's Resources in Collective Households: Identification, Estimation, and an Application to Child Poverty in Malawi." The American Economic Review, 103(1): 438-471.

Ehrlich, Isaac, and Francis T. Lui. 1991. "Intergenerational trade, longevity, and economic growth." Journal of Political Economy, 1029-1059.

Estevan, Fernanda, and Jean-Marie Baland. 2007. "Mortality risks, education and child labor." Journal of Development Economics, 84(1): 118-137.

Farouk, Salah E., Amagana Dolo, Sàndor Bereczky, Bourema Kouriba, Boubacar Maiga, Anna Färnert, Hedvig Perlmann, Masashi Hayano, Scott M. Montgomery, and Ogobara K. Doumbo. 2005. "Different antibody-and cytokine-mediated 
responses to Plasmodium falciparum parasite in two sympatric ethnic tribes living in Mali." Microbes and Infection, 7(1): 110-117.

Fernando, Deepika, Damani De Silva, Richard Carter, Kamini N. Mendis, and Rajitha Wickremasinghe. 2006. "A randomized, double-blind, placebo-controlled, clinical trial of the impact of malaria prevention on the educational attainment of school children." The American Journal of Tropical Medicine and Hygiene, 74(3): 386-393.

Fernando, Deepika, D. M. Gunawardena, M. Bandara, D. De Silva, R. Carter, K. N. Mendis, and A. R. Wickremasinghe. 2003. "The impact of repeated malaria attacks on the school performance of children." The American Journal of Tropical Medicine and Hygiene, 69(6): 582-588.

Hampshire, Kate, and Sara Randall. 2000. "Pastoralists, agropastoralists and migrants: interactions between fertility and mobility in northern Burkina Faso." Population Studies, 54(3): 247-261.

Hazan, Moshe, and Hosny Zoabi. 2006. "Does longevity cause growth? A theoretical critique." Journal of Economic Growth, 11(4): 363-376.

Hill, A. G., and A. Thiam. 1987. "Marriage inheritance and fertility amongst the Malian Fulani." Population Studies Center working paper.

Holding, P. A., and R. W. Snow. 2001. "Impact of Plasmodium falciparum malaria on performance and learning: review of the evidence." The American journal of tropical medicine and hygiene, 64(1 suppl): 68-75.

Holt, Charles A., and Susan K. Laury. 2002. "Risk aversion and incentive effects." American Economic Review, 92(5): 1644-1655.

Howes, Rosalind E., Frédéric B. Piel, Anand P. Patil, Oscar A. Nyangiri, Peter W. Gething, Mewahyu Dewi, Mariana M. Hogg, Katherine E. Battle, Carmencita D. Padilla, J. Kevin Baird, and Simon I. Hay. 2012. "G6PD Deficiency Prevalence and Estimates of Affected Populations in Malaria Endemic Countries: A Geostatistical Model-Based Map." PLoS Medicine, 9(11): e1001339. 
Imbens, Guido W., and Joshua D. Angrist. 1994. "Identification and Estimation of Local Average Treatment Effects." Econometrica, 62(2): 467-475.

Jayachandran, Seema, and Adriana Lleras-Muney. 2009. "Life Expectancy and Human Capital Investments: Evidence from Maternal Mortality Declines." The Quarterly Journal of Economics, 124(1): 349-397.

Jukes, Matthew CH, Margaret Pinder, Elena L. Grigorenko, Helen Baños Smith, Gijs Walraven, Elisa Meier Bariau, Robert J. Sternberg, Lesley J. Drake, Paul Milligan, and Yin Bun Cheung. 2006. "Long-term impact of malaria chemoprophylaxis on cognitive abilities and educational attainment: follow-up of a controlled trial." PLOS Hub for Clinical Trials, 1(4): e19.

Kalemli-Ozcan, Sebnem. 2003. "A stochastic model of mortality, fertility, and human capital investment." Journal of Development Economics, 70(1): 103-118.

Kurtzhals, Jørgen AL, Mark M. Addae, Bartholomew D. Akanmori, Samuel Dunyo, Kwadjo A. Koram, Maxwell A. Appawu, Francis K. Nkrumah, and Lars Hviid. 1999. "Anaemia caused by asymptomatic Plasmodium falciparum infection in semiimmune African schoolchildren." Transactions of the Royal Society of Tropical Medicine and Hygiene, 93(6): 623-627.

Lagerlöf, Nils-Petter. 2003. "From Malthus to Modern Growth: Can Epidemics Explain the Three Regimes?*." International Economic Review, 44(2): 755-777.

Lisa, A., P. Astolfi, A. Degioanni, C. Di Pasquale, and G. Zei. 1994. "Differential fertility as a mechanism maintaining balanced polymorphisms in Sardinia." Human Biology, 66(4): 683-698.

Lucas, Adrienne M. 2010. "Malaria eradication and educational attainment: evidence from Paraguay and Sri Lanka." American Economic Journal: Applied Economics, $2(2): 46-71$.

Lucas, Adrienne M. 2013. "The impact of malaria eradication on fertility." Economic Development and Cultural Change, 61(3): 607-631. 
Modiano, David, Gaia Luoni, Bienvenu Sodiomon Sirima, Alessandra Lanfrancotti, Vincenzo Petrarca, Fulvio Cruciani, Jacques Simporé, Bianca Maria Ciminelli, Enrica Foglietta, and Paola Grisanti. 2001. "The lower susceptibility to Plasmpdium falciparum malaria of Fulani of Burkina Faso (West Africa) is associated with low frequencies of classic malaria-resistance genes." Transactions of the Royal Society of Tropical Medicine and Hygiene, 95(2): 149-152.

Modiano, D., V. Petrarca, B. S. Sirima, A. Bosman, I. Nebie, D. Diallo, L. Lamizana, F. Esposito, and M. Coluzzi. 1995. "Plasmodium falciparum malaria in sympatric ethnic groups of Burkina Faso, west Africa." Parassitologia, 37(2-3): 255-259.

Mung'ala-Odera, Victor, Robert W. Snow, and Charles R. J. C. Newton. 2004. "The Burden of the Neurocognitive Impairment Associated with Plasmodium Falciparum Malaria in Sub-Saharan Africa." The American Journal of Tropical Medicine and Hygiene, 71(2 suppl): 64-70.

Murray, Christopher JL, Lisa C. Rosenfeld, Stephen S. Lim, Kathryn G. Andrews, Kyle J. Foreman, Diana Haring, Nancy Fullman, Mohsen Naghavi, Rafael Lozano, and Alan D. Lopez. 2012. "Global malaria mortality between 1980 and 2010: a systematic analysis." The Lancet, 379(9814): 413-431.

Nankabirwa, Joaniter, Bonnie Wandera, Noah Kiwanuka, Sarah G. Staedke, Moses R. Kamya, and Simon J. Brooker. 2013. "Asymptomatic Plasmodium Infection and Cognition among Primary Schoolchildren in a High Malaria Transmission Setting in Uganda." The American Journal of Tropical Medicine and Hygiene, 88(6): 1102-1108.

Nasr, Amre, Nnaemeka C. Iriemenam, Hayder A. Giha, Halima A. Balogun, Robin F. Anders, Marita Troye-Blomberg, Gehad ElGhazali, and Klavs Berzins. 2009. "FcRIIa (CD32) polymorphism and anti-malarial IgG subclass pattern among Fulani and sympatric ethnic groups living in eastern Sudan." Malaria Journal, $8(1): 43$.

New, Mark, David Lister, Mike Hulme, and Ian Makin. 2002a. "A high-resolution data set of surface climate over global land areas." Climate Research, 21(1): 1-25. 
New, Mark, David Lister, Mike Hulme, and Ian Makin. 2002b. "A high-resolution data set of surface climate over global land areas." Climate research, 21(1): 1-25.

Ngoungou, E. B., B. Poudiougou, O. Dulac, A. Dicko, M. P. Boncoeur, A. M. Traore, D. Coulibaly, M. M. Keita, P. M. Preux, and O. K. Doumbo. 2007. "Séquelles neurologiques persistantes dues au paludisme cérébral dans une cohorte d'enfants au Mali." Revue Neurologique, 163(5): 583-588.

Raven, J. C. 1984. "JH Court, and J. Raven. 1984." Manual for Raven's progressive matrices and vocabulary scales. Section 2: Coloured progressive matrices.

Savigny, M., C. Barbier, R. Coupey-Le Roy, J. Girard, and G. Roussel. 2001. "Batelem-R." Batterie d'épreuves pour l'école élémentaire. Cycle II et première année du cycle III. Paris: EAP.

Smith, David L., F. Ellis McKenzie, Robert W. Snow, and Simon I. Hay. 2007. "Revisiting the basic reproductive number for malaria and its implications for malaria control." PLoS Biology, 5(3): e42.

Soares, Rodrigo R. 2005. "Mortality reductions, educational attainment, and fertility choice." American Economic Review, 580-601.

Thuilliez, Josselin, Mahamadou S. Sissoko, Ousmane B. Toure, Paul Kamate, Jean-Claude Berthélemy, and Ogobara K. Doumbo. 2010. "Malaria and primary education in Mali: A longitudinal study in the village of Donéguébougou." Social Science \& Medicine, 71(2): 324-334.

Vafa, Manijeh, Bakary Maiga, Klavs Berzins, Masashi Hayano, Sandor Bereczky, Amagana Dolo, Modibo Daou, Charles Arama, Bourema Kouriba, Anna Färnert, Ogobara K. Doumbo, and Marita Troye-Blomberg. 2007. "Associations between the IL-4 -590 T allele and Plasmodium falciparum infection prevalence in asymptomatic Fulani of Mali." Microbes and Infection / Institut Pasteur, 9(9): 1043-1048.

Vafa, Manijeh, Elisabeth Israelsson, Bakary Maiga, Amagana Dolo, Ogobara K. Doumbo, and Marita Troye-Blomberg. 2009. "Relationship between immunoglobulin isotype response to Plasmodium falciparum blood stage antigens and parasitological 
indexes as well as splenomegaly in sympatric ethnic groups living in Mali." Acta Tropica, 109(1): 12-16.

Venkataramani, Atheendar S. 2012. "Early life exposure to malaria and cognition in adulthood: Evidence from Mexico." Journal of Health Economics, 31(5): 767-780.

Williams, Thomas N. 2006. "Human red blood cell polymorphisms and malaria." Current Opinion in Microbiology, 9(4): 388-394.

Zei, G., A. Lisa, and P. Astolfi. 1990. "Fertility and malaria in Sardinia." Annals of Human Biology, 17(4): 315-330. 
Table 1: Descriptive Statistics

\begin{tabular}{|c|c|c|c|c|c|c|c|c|c|c|c|c|c|c|c|c|}
\hline & \multicolumn{7}{|c|}{ Malarious season } & \multicolumn{7}{|c|}{ Non-Malarious season } & \multicolumn{2}{|c|}{ Diff-in-Diff } \\
\hline & \multicolumn{3}{|c|}{ Fulani (56) } & \multicolumn{3}{|c|}{ Non Fulani (240) } & \multirow{2}{*}{$\frac{\text { Diff }}{\text { Mean }}$} & \multicolumn{3}{|c|}{ Fulani (51) } & \multicolumn{3}{|c|}{ Non Fulani (240) } & \multirow{2}{*}{$\begin{array}{l}\text { Diff } \\
\text { Mean }\end{array}$} & \multirow[b]{2}{*}{$\mathrm{N}$} & \multirow[b]{2}{*}{ Mean } \\
\hline & $\mathrm{N}$ & Mean & $\mathrm{Sd}$ & $\mathrm{N}$ & Mean & $\mathrm{Sd}$ & & $\mathrm{N}$ & Mean & $\mathrm{Sd}$ & $\mathrm{N}$ & Mean & $\mathrm{Sd}$ & & & \\
\hline \multicolumn{17}{|l|}{ Malaria } \\
\hline PCR positive & 56 & 0.679 & 0.471 & 240 & 0.871 & 0.336 & $-0.192^{* * *}$ & 51 & 0.235 & 0.428 & 240 & 0.25 & 0.43 & -0.015 & 587 & $-0.178^{*}$ \\
\hline Microscopy Positive & 56 & 0.250 & 0.436 & 240 & 0.661 & 0.474 & $-0.411^{* * *}$ & 51 & 0.040 & 0.197 & 240 & 0.162 & 0.37 & $-0.122^{* *}$ & 587 & $-0.288^{* * *}$ \\
\hline Parasite Density (Microscopy) & 56 & 5.500 & 12.933 & 240 & 89.419 & 329.984 & $-83.919 * * *$ & 51 & 0.140 & 0.756 & 240 & 12.76 & 75.1 & -12.621 & 587 & $-71.297^{* * *}$ \\
\hline \multicolumn{17}{|l|}{ Malaria Symptoms } \\
\hline Fever $($ Temp $>37.5 \mathrm{C})$ & 56 & 0.143 & 0.353 & 240 & 0.188 & 0.391 & -0.045 & 51 & 0.039 & 0.196 & 236 & 0.03 & 0.170 & 0.010 & 583 & -0.054 \\
\hline Cephalgia & 56 & 0.054 & 0.227 & 240 & 0.146 & 0.354 & -0.092 & 51 & 0.196 & 0.401 & 236 & 0.093 & 0.290 & $0.103^{*}$ & 583 & $-0.195^{* * *}$ \\
\hline Vomiting & 56 & 0.000 & 0.000 & 240 & 0.013 & 0.111 & -0.013 & 51 & 0.059 & 0.238 & 236 & 0.000 & 0.000 & 0.000 & 583 & $-0.013^{*}$ \\
\hline Diarrhea & 56 & 0.018 & 0.134 & 240 & 0.004 & 0.065 & 0.014 & 51 & 0.157 & 0.464 & 236 & 0.004 & 0.070 & -0.004 & 583 & 0.018 \\
\hline Abdominal pain & 56 & 0.107 & 0.312 & 240 & 0.083 & 0.277 & 0.024 & 51 & -1.924 & 1.496 & 236 & 0.055 & 0.230 & 0.004 & 583 & 0.020 \\
\hline \multicolumn{17}{|l|}{ Health } \\
\hline Splenomegaly ( Hacket classification) & 56 & 0.339 & 0.745 & 240 & 0.100 & 0.375 & $0.239 * * *$ & 51 & 0.157 & 0.464 & 236 & 0.059 & 0.290 & 0.098 & 583 & 0.142 \\
\hline BMI for age z-score & 56 & -1.696 & 1.432 & 240 & -0.473 & 1.032 & $-1.224^{* * *}$ & 51 & -1.924 & 1.496 & 236 & -0.461 & 1.020 & $-1.463^{* * *}$ & 583 & 0.239 \\
\hline Haemoglobin concentration & 56 & 11.498 & 1.682 & 240 & 11.884 & 1.193 & $-0.386^{*}$ & 47 & 11.172 & 1.646 & 232 & 11.99 & 1.300 & $-0.821^{* * *}$ & 575 & $0.436^{* * *}$ \\
\hline Presence of intestinal parasites & 36 & 0.361 & 0.487 & 211 & 0.455 & 0.499 & -0.094 & - & - & - & - & - & - & - & - & \\
\hline Presence of eggs of Bilharzia in urine & 42 & 0.690 & 0.468 & 197 & 0.604 & 0.490 & 0.086 & - & - & - & - & - & - & - & - & \\
\hline \multicolumn{17}{|l|}{ Cognitive tests } \\
\hline Raven's Progressive Matrices & 45 & -0.416 & 0.911 & 226 & -0.223 & 0.979 & -0.194 & 50 & 0.231 & 1.022 & 229 & 0.236 & 0.953 & -0.005 & 550 & -0.189 \\
\hline \multicolumn{17}{|l|}{ Academic school outcomes } \\
\hline Educational PCA score & 45 & -0.306 & 1.358 & 201 & -0.417 & 1.314 & 0.111 & 44 & 0.661 & 1.197 & 214 & 0.315 & 1.317 & 0.346 & 504 & -0.235 \\
\hline Educational average score & 56 & -0.074 & 0.732 & 240 & -0.140 & 0.626 & 0.066 & 51 & 0.194 & 0.628 & 236 & 0.130 & 0.638 & 0.064 & 583 & 0.002 \\
\hline \multicolumn{17}{|l|}{ Others } \\
\hline Age & 56 & 10.179 & 2.629 & 240 & 11.000 & 2.729 & $-0.821^{*}$ & 51 & 10.157 & 2.501 & 239 & 10.946 & 2.747 & -0.789 & 586 & -0.196 \\
\hline Gender (Female) & 56 & 0.554 & 0.502 & 240 & 0.496 & 0.501 & 0.058 & 51 & 0.588 & 0.497 & 239 & 0.502 & 0.501 & 0.086 & 586 & -0.028 \\
\hline
\end{tabular}

Notes: This table provides the average or proportion of selected variables before and after the seasonal change for the different groups. The simple difference 
columns use simple Student's $t$-tests. The equation estimated in the last column (Diff-in-Diff) is similar to equation (1) without controls. Put differently the last column provides $\gamma_{1}$ from an OLS estimation of this equation: $Y_{i t}=\alpha_{2}+\gamma_{1}\left[\right.$ Post $_{t} \times$ NonFulani $\left._{i}\right]+\gamma_{2}$ Post $_{t}+\gamma_{3}$ NonFulani $_{i}+\epsilon_{i t}$, where standard errors are clustered at the family level. Note that using other clustering options, e.g. at the ethnic level, does not change the results. ${ }^{*}, * *$ and ${ }^{* * *}$ indicate significance at the 10,5 and $1 \%$ levels. 
Table 2: Effect Malaria on Cognitive and Educational Outcomes: Local Average

Treatment Effect.

\begin{tabular}{|c|c|c|c|c|c|c|}
\hline & \multicolumn{5}{|c|}{ Whole Sample (Fulani \& Non Fulani) } & \multirow{2}{*}{$\begin{array}{l}\text { Fulani } \\
\text { \& Dogon only } \\
(6)\end{array}$} \\
\hline & $(1)$ & $(2)$ & $(3)$ & $(4)$ & $(5)$ & \\
\hline Cognition score (Raven) & $\begin{array}{l}-0.370^{* * *} \\
(0.075)\end{array}$ & $\begin{array}{l}-0.777^{* * *} \\
(0.115)\end{array}$ & $\begin{array}{l}-0.692^{* * *} \\
(0.105)\end{array}$ & $\begin{array}{l}-0.712^{* * *} \\
(0.106)\end{array}$ & $\begin{array}{l}-0.877^{* * *} \\
(0.124)\end{array}$ & $\begin{array}{l}-0.880^{* * *} \\
(0.132)\end{array}$ \\
\hline $\mathrm{N}$ & 550 & 550 & 550 & 542 & 504 & 474 \\
\hline R-squared & 0.034 & - & - & - & - & - \\
\hline Durbin-Wu-Hausman chi-sq test & - & $54.47^{* * *}$ & $55.861^{* * *}$ & $54.061^{* * *}$ & $45.747^{* * *}$ & $42.574^{* * *}$ \\
\hline Angrist-Pischke first-stage F statistics & - & $115.54^{* * *}$ & $126.51^{* * *}$ & $128.49^{* * *}$ & $152.75^{* * *}$ & $139.71^{* * *}$ \\
\hline Educational score (PCA score) & $\begin{array}{l}-0.388^{* * *} \\
(0.111)\end{array}$ & $\begin{array}{l}-1.275^{* * *} \\
(0.149)\end{array}$ & $\begin{array}{l}-1.163^{* * *} \\
(0.150)\end{array}$ & $\begin{array}{l}-1.193^{* * *} \\
(0.154)\end{array}$ & $\begin{array}{l}-1.157^{* * *} \\
(0.164)\end{array}$ & $\begin{array}{l}-1.173^{* * *} \\
(0.171)\end{array}$ \\
\hline $\mathrm{N}$ & 504 & 504 & 503 & 498 & 430 & 402 \\
\hline R-squared & 0.020 & - & - & - & - & - \\
\hline Durbin-Wu-Hausman chi-sq test & - & $51.309^{* * *}$ & $52.558^{* * *}$ & $50.507^{* * *}$ & $42.853^{* * *}$ & $39.652^{* * *}$ \\
\hline Angrist-Pischke first-stage F statistics & - & $104.65^{* * *}$ & $123.62^{* * *}$ & $130.42^{* * *}$ & $166.7^{* * *}$ & $152.82^{* * *}$ \\
\hline Educational score (Av. score) & $\begin{array}{l}-0.142^{* * *} \\
(0.046)\end{array}$ & $\begin{array}{l}-0.452^{* * *} \\
(0.065)\end{array}$ & $\begin{array}{l}-0.404^{* * *} \\
(0.057)\end{array}$ & $\begin{array}{l}-0.423^{* * *} \\
(0.057)\end{array}$ & $\begin{array}{l}-0.424^{* * *} \\
(0.068)\end{array}$ & $\begin{array}{l}-0.426^{* * *} \\
(0.071)\end{array}$ \\
\hline $\mathrm{N}$ & 583 & 583 & 582 & 574 & 556 & 526 \\
\hline R-squared & 0.012 & - & - & - & - & - \\
\hline Durbin-Wu-Hausman chi-sq test & - & $53.281^{* * *}$ & $54.172^{* * *}$ & $52.934^{* * *}$ & $42.316^{* * *}$ & $39.403^{* * *}$ \\
\hline Angrist-Pischke first-stage F statistics & - & $118.79^{* * *}$ & $136.98^{* * *}$ & $140.11^{* * *}$ & $143.18^{* * *}$ & $131.69^{* * *}$ \\
\hline OLS & Yes & No & No & No & No & No \\
\hline 2SLS & No & Yes & Yes & Yes & Yes & Yes \\
\hline Malaria symptoms & No & No & Yes & Yes & Yes & Yes \\
\hline Health controls & No & No & No & Yes & Yes & Yes \\
\hline Wihtin Child fixed effects & No & No & No & No & Yes & Yes \\
\hline
\end{tabular}

Notes: This table provides the Local Average Treatment Effect. Each cell reports the coefficient from a separate regression corresponding to equation (2) where the first stage is equation (3), provided in Table 4. The measure used for malaria is the PCR measure. We provide similar tables for the other malaria 
measurements (microscopy either binary or continuous) in Table A2. The last column reduces the sample to the Dogon ethnic group for the non-Fulani group, whereas all other columns include all non-Fulani groups. Malaria controls include all malaria symptoms provided in Table 1 (five dummies for fever, cephalgia, vomiting, diarrhea, and abdominal pain). Health controls include splenomegaly, BMI-for-age, haemoglobin concentration. The low $p$-values from the Durbin-Wu-Hausman test indicate that malaria infections should be treated as endogenous. The Angrist-Pischke (AP) first-stage F statistics are tests of weak identification and show that endogenous regressor is not "weakly identified". Standard errors are reported in parenthesis and clustered at the family level. Note that using other clustering options, e.g. at the ethnic level, does not change the results. ${ }^{*}, * *$ and $* * *$ indicate significance at the 10,5 and $1 \%$ levels. 
Table 3: First stage estimates (Linear Probability Model)

\begin{tabular}{|c|c|c|c|c|c|c|c|c|}
\hline & \multicolumn{4}{|c|}{ Whole Sample (Fulani \& Non Fulani) } & \multicolumn{4}{|c|}{ Fulani \& Dogon only } \\
\hline & $(1)$ & $(2)$ & $(3)$ & $(4)$ & $(5)$ & $(6)$ & $(7)$ & (8) \\
\hline \multirow[t]{2}{*}{ Non-Fulani } & $0.192^{* * *}$ & $0.197^{* * *}$ & $0.244^{* * *}$ & - & $0.188^{* * *}$ & $0.193^{* * *}$ & $0.240^{* * *}$ & - \\
\hline & -0.061 & -0.061 & -0.064 & & -0.061 & -0.06 & -0.065 & \\
\hline \multirow[t]{2}{*}{ Post } & $-0.443^{* * *}$ & $-0.441^{* * *}$ & $-0.444^{* * *}$ & $-0.402^{* * *}$ & $-0.443^{* * *}$ & $-0.438^{* * *}$ & $-0.440^{* * *}$ & $-0.399^{* * *}$ \\
\hline & -0.095 & -0.094 & -0.096 & -0.107 & -0.095 & -0.094 & -0.096 & -0.108 \\
\hline \multirow[t]{2}{*}{ Non-Fulani x Post } & $-0.178^{*}$ & $-0.185^{*}$ & $-0.177^{*}$ & $-0.206^{*}$ & $-0.181^{*}$ & $-0.192^{*}$ & $-0.183^{*}$ & $-0.211^{*}$ \\
\hline & -0.100 & -0.100 & -0.102 & -0.113 & -0.101 & -0.101 & -0.103 & -0.113 \\
\hline$N$ & 587 & 583 & 575 & 575 & 554 & 551 & 544 & 544 \\
\hline R-squared & 0.359 & 0.361 & 0.37 & 0.511 & 0.359 & 0.362 & 0.368 & 0.513 \\
\hline Malaria symptoms & No & Yes & Yes & Yes & No & Yes & Yes & Yes \\
\hline Health controls & No & No & Yes & Yes & No & No & Yes & Yes \\
\hline Wihtin Child fixed effects & No & No & No & Yes & No & No & No & Yes \\
\hline
\end{tabular}

Notes: This table provides the first stage of Table 2 and columns (4) and (8) correspond exactly to equation (3). The last column reduces the sample to the Dogon ethnic group as the non-Fulani group, whereas all other columns include all non-Fulani groups. Malaria controls include all malaria symptoms provided in Table 1 (five dummies for fever, cephalgia, vomiting, diarrhea, and abdominal pain). Health controls include splenomegaly, BMI-for-age, haemoglobin concentration. Standard errors are reported in parenthesis and clustered at the family level. Note that using other clustering options, e.g. at the ethnic level, does not change the results. ${ }^{*}, * *$ and $* * *$ indicate significance at the 10,5 and $1 \%$ levels. 
Table 4: Testing other mechanisms

\begin{tabular}{|c|c|c|c|c|c|c|}
\hline & \multicolumn{3}{|c|}{ Whole Sample (Fulani \& Non-Fulani) } & \multicolumn{3}{|c|}{ Fulani \& Dogon only } \\
\hline & $\begin{array}{l}\text { Cognition } \\
\text { score } \\
\text { (Raven) }\end{array}$ & $\begin{array}{l}\text { Educational } \\
\text { score } \\
\text { (PCA score) }\end{array}$ & $\begin{array}{l}\text { Educational } \\
\text { score } \\
\text { (Av. score) }\end{array}$ & $\begin{array}{l}\text { Cognition } \\
\text { score } \\
\text { (Raven) }\end{array}$ & $\begin{array}{l}\text { Educational } \\
\text { score } \\
\text { (PCA score) }\end{array}$ & $\begin{array}{l}\text { Educational } \\
\text { score } \\
\text { (Av. score) }\end{array}$ \\
\hline PCR postive & $\begin{array}{l}-0.933^{* * *} \\
(0.185)\end{array}$ & $\begin{array}{l}-1.564^{* * *} \\
(0.480)\end{array}$ & $\begin{array}{l}-0.497^{* * *} \\
(0.089)\end{array}$ & $\begin{array}{l}-0.901^{* * *} \\
(0.188)\end{array}$ & $\begin{array}{l}-1.457^{* * *} \\
(0.457)\end{array}$ & $\begin{array}{l}-0.475^{* * *} \\
(0.094)\end{array}$ \\
\hline Hgb Level & $\begin{array}{l}-0.832 \\
(0.780)\end{array}$ & $\begin{array}{l}-3.227 \\
(2.735)\end{array}$ & $\begin{array}{l}-0.511 \\
(0.316)\end{array}$ & $\begin{array}{l}-0.876 \\
(0.821)\end{array}$ & $\begin{array}{l}-3.435 \\
(3.027)\end{array}$ & $\begin{array}{l}-0.548 \\
(0.334)\end{array}$ \\
\hline$N$ & 504 & 430 & 556 & 474 & 402 & 526 \\
\hline PCR postive & $\begin{array}{l}-1.081^{* * *} \\
(0.266)\end{array}$ & $\begin{array}{l}-1.379^{* * *} \\
(0.269)\end{array}$ & $\begin{array}{l}-0.545^{* * *} \\
(0.094)\end{array}$ & $\begin{array}{l}-1.049^{* * *} \\
(0.256)\end{array}$ & $\begin{array}{l}-1.346^{* * *} \\
(0.268)\end{array}$ & $\begin{array}{l}-0.527^{* * *} \\
(0.095)\end{array}$ \\
\hline At least one symptom & $\begin{array}{l}2.251 \\
(1.920)\end{array}$ & $\begin{array}{l}3.078 \\
(1.945)\end{array}$ & $\begin{array}{l}0.877 \\
(0.568)\end{array}$ & $\begin{array}{l}2.35 \\
(2.000)\end{array}$ & $\begin{array}{l}3.078 \\
(1.959)\end{array}$ & $\begin{array}{l}0.908 \\
(0.588)\end{array}$ \\
\hline$N$ & 504 & 430 & 556 & 474 & 402 & 526 \\
\hline PCR postive & $\begin{array}{l}-1.427^{* * *} \\
(0.394)\end{array}$ & $\begin{array}{l}-1.472^{* * *} \\
(0.313)\end{array}$ & $\begin{array}{l}-0.553^{* * *} \\
(0.147)\end{array}$ & $\begin{array}{l}-1.347^{* * *} \\
(0.385)\end{array}$ & $\begin{array}{l}-1.403^{\text {*** }} \\
(0.296)\end{array}$ & $\begin{array}{l}-0.534^{* * *} \\
(0.145)\end{array}$ \\
\hline Treatment & $\begin{array}{l}0.502^{*} \\
(0.292)\end{array}$ & $\begin{array}{l}0.315 \\
(0.222)\end{array}$ & $\begin{array}{l}0.132 \\
(0.103)\end{array}$ & $\begin{array}{l}0.436 \\
(0.286)\end{array}$ & $\begin{array}{l}0.243 \\
(0.210)\end{array}$ & $\begin{array}{l}0.116 \\
(0.100)\end{array}$ \\
\hline$N$ & 502 & 430 & 552 & 472 & 402 & 522 \\
\hline 2SLS & Yes & Yes & Yes & Yes & Yes & Yes \\
\hline Malaria symptoms & Yes & Yes & Yes & Yes & Yes & Yes \\
\hline Health controls & Yes & Yes & Yes & Yes & Yes & Yes \\
\hline Wihtin Child Fixed effects & Yes & Yes & Yes & Yes & Yes & Yes \\
\hline
\end{tabular}

Notes: This table provides the Local Average Treatment Effect. Each cell reports the coefficient from a separate regression corresponding to equation (2) where we instrument both malaria and the additional health variables simultaneously following equation (3) where two health factors are considered as endogenous. The measure used for malaria is the PCR measure. The last column reduces the sample to the Dogon ethnic group as the non-Fulani group, whereas all other columns include all non-Fulani groups. Standard errors are reported in parenthesis and clustered at the family level. Note that using other clustering options, e.g. at the ethnic level, does not change the results. ${ }^{*}, *$ and $* * *$ indicate significance at the 10,5 and $1 \%$ levels. 
Table 5: Effect of Malaria on Cognitive and Educational Outcomes (replacing missing values)

\begin{tabular}{|c|c|c|c|c|c|c|}
\hline & \multicolumn{5}{|c|}{ Whole Sample (Fulani \& Non Fulani) } & \multirow{2}{*}{$\begin{array}{l}\text { Fulani } \\
\text { \& Dogon only } \\
(6)\end{array}$} \\
\hline & $(1)$ & $(2)$ & $(3)$ & $(4)$ & $(5)$ & \\
\hline \multirow[t]{2}{*}{ Cognition score (Raven) } & $-0.433^{* * *}$ & $-0.967^{* * *}$ & $-0.864^{* * *}$ & $-0.886^{* * *}$ & $-1.019 * * *$ & $-1.029^{* * *}$ \\
\hline & $(0.078)$ & $(0.127)$ & $(0.117)$ & $(0.117)$ & $(0.129)$ & $(0.136)$ \\
\hline$N$ & 565 & 565 & 565 & 557 & 532 & 502 \\
\hline \multirow[t]{2}{*}{ Educational score (PCA score) } & $-0.735^{* * *}$ & $-2.290^{* * *}$ & $-2.231^{* * *}$ & $-2.224^{* * *}$ & $-2.071^{* * *}$ & $-2.101^{* * *}$ \\
\hline & $(0.122)$ & $(0.215)$ & $(0.224)$ & $(0.216)$ & $(0.219)$ & $(0.226)$ \\
\hline$N$ & 550 & 550 & 549 & 543 & 502 & 472 \\
\hline \multirow[t]{2}{*}{ Educational score (Av. score) } & $-0.142^{* * *}$ & $-0.452^{* * *}$ & $-0.404^{* * *}$ & $-0.423^{* * *}$ & $-0.424^{* * *}$ & $-0.426^{* * *}$ \\
\hline & $(0.046)$ & $(0.065)$ & $(0.057)$ & $(0.057)$ & $(0.068)$ & $(0.071)$ \\
\hline$N$ & 583 & 583 & 582 & 574 & 556 & 526 \\
\hline OLS & Yes & No & No & No & No & No \\
\hline 2SLS & No & Yes & Yes & Yes & Yes & Yes \\
\hline Malaria symptoms & No & Yes & Yes & Yes & Yes & Yes \\
\hline Health controls & No & No & Yes & Yes & Yes & Yes \\
\hline Wihtin Child fixed effects & No & No & No & No & Yes & Yes \\
\hline
\end{tabular}

Notes: This table is similar to Table 2 where all the missing educational outcomes for the Fulani were coded at the maximum value of the outcome in the post period and all the missing educational outcomes for the Non-Fulani were coded at the minimum value of the outcome. Each cell reports the coefficient from a separate regression corresponding to equation (2) where the first stage is equation (3), provided in Table 4. The measure used for malaria is the PCR measure. We provide similar tables for the other malaria measures (microscopy either binary or continuous) in Table A2. The last column reduces the sample to the Dogon ethnic group as the non-Fulani group, whereas all other columns include all non-Fulani groups. Malaria controls include all malaria symptoms provided in Table 1 (five dummies for fever, cephalgia, vomiting, diarrhea, and abdominal pain). Health controls include splenomegaly, BMI-for-age, haemoglobin 
concentration. Standard errors are reported in parenthesis and clustered at the family level. Note that using other clustering options, e.g. at the ethnic level, does not change the results. ${ }^{*},{ }^{* *}$ and ${ }^{* * *}$ indicate significance at the 10,5 and $1 \%$ levels. 
Table 6: Stylized facts at the family level (baseline survey and Mali Demographic and Health Surveys)

\begin{tabular}{llll}
\hline \hline & $(1)$ & $(2)$ & $(3)$ \\
\hline & Educational & & Total children \\
& Investment & Total number & ever born \\
& per children & of children & per woman \\
& per year $\quad$ in & per household & $(\mathrm{DHS})$ \\
& XOF $)$ & & \\
\hline Non-Fulani & $2,847^{* *}$ & $0.949^{* * *}$ & $0.313^{*}$ \\
& $(501.400)$ & $(0.037)$ & $(0.189)$ \\
Wealth Index & -199.4 & $0.188^{* * *}$ & $0.135^{* *}$ \\
& $(99.700)$ & $(0.016)$ & $(0.055)$ \\
Constant & $7,166^{* * *}$ & $6.176^{* * *}$ & $-3.297^{* * *}$ \\
& $(570.200)$ & $(0.055)$ & $(0.321)$ \\
\hline R-squared & 0.03 & & 989 \\
\hline \hline
\end{tabular}

Notes: This table provides stylised facts on fertility and educational investments in Mali. Cluster-robust Standard errors (at the ethnic level) are in parentheses. *, ** and *** indicate significance at the 10, 5 and $1 \%$ levels. 


\section{Appendix}

\subsection{Appendix A: Data}

\subsubsection{Cognitive tests and educational outcomes}

We focused on a set of outcomes that are intended to capture a child's human capital accumulation. These include specific tests which have already been used before in Mali. Tests were grade-specific, but not time-specific for two main reasons. First, children get used to the procedure quickly, and second, it is possible to account for learning progression and achievement.

Cognitive outcomes are Raven's Progressive Matrices test scores (Raven, 1984). Raven matrices are available in three different forms for participants of different abilities. Only two of them were used for the purpose of this study: Raven's Standard Progressive Matrices and Raven's Coloured Progressive Matrices. Raven tests measure general mental ability and offer information about individual capacity for analyzing and solving problems, abstract reasoning, and the ability to learn. Colored Progressive Matrices were used for children aged 5 to 11 years old and Standard Progressive Matrices were used for older children, following Raven's recommendation. Results from these tests were then standardized by grade across the two follow-ups.

Specific educational tests were developed with the team of Diankabou teachers. They were derived from validated questions already used in other studies (Jukes et al., 2006; Thuilliez et al., 2010) and French models for primary educational tests: BatelemR (Savigny et al., 2001) and Boehm3 (Boehm, 2001). They were then adapted to the village context. This was a multi-step process. First, new questions or statements were developed, based on the format of the original test questions. Next, the content of the assessment was modified but the basic format remained the same. The teachers assessed the suitability of the content to the age and grade-level programs and defined five categories: mathematics, vocabulary, writing, reading, and visual memory. All tests were administered by the teachers in one session lasting around 45 minutes in the school. All tests were standardized by class, but not by cross-sectional follow-up to take into account the evolution of scores over time. A principal component analysis was then performed on the five variables to calculate an educational 
function score (Bartlett, 1937). Condensing the information contained in the original variables into one dimension is justified as the aim is not to assess the impact of malaria only on particular skills, but on the common underlying process involved in knowing, learning, and understanding. In addition, the validity of such an educational function score as a measure of educational achievement in Mali has been tested in Thuilliez et al. (2010), where a high significant correlation between the annual average standardized academic school marks and the annual educational function score was found. However, although the educational function score seems to be a good measure of educational achievement, we also use an arithmetic average as a robustness test ${ }^{20}$.

\subsubsection{Health status}

In order to detect an ongoing P. falciparum malaria infection, finger prick blood was collected on filter papers for PCR analyses. Malaria infection is defined as a PCR positive sample (binary variable). This technique is much more sensitive and specific than miscroscopy, as previously noted by Anchinmane and Shedge (2011). In addition, each participant underwent a full clinical examination. Clinical symptoms compatible with malaria are body temperature higher than 37.5 Celsius degrees, cephalgia, vomiting, diarrhea or abdominal pain. Note that most malaria cases were asymptomatic cases (i.e., without any symptoms; Table 1). This is consistent with epidemiological studies (Clarke et al., 2004; Dicko et al., 2005). School-age children are the age group most commonly infected with malaria parasites. These infections are usually asymptomatic (without clinical symptoms), so go undetected and thus never get treated. In this study, only acute cases of clinical illness (of any type) were treated immediately and monitored by the medical team directly in the field ${ }^{21}$. Splenomegaly, an enlargement of the spleen resulting from an abnormal immune response to repeated attacks of malaria, was assessed via spleen measurement using the Hackett classification (Hackett, 1944).

The weight and height of each child was measured using an electronic scale and stadiometer respectively. The age of each child was calculated in years and months using the date of birth given by the birth certificate, according to school records and confirmed, if necessary,

\footnotetext{
${ }^{20}$ Note that the number of observations for the two academic school outcomes differ slightly because the PCA score excludes all missing values whereas the arithmetic average ignores missing values.

${ }^{21}$ Treatment against asymptomatic forms was provided to all pupils at the end of the study.
} 
by the village census. In order to compare children of different ages by sex, the anthropometric measurements were converted into Body Mass Index (BMI)-for-age z-score, using the 2000 Centre for Disease Control and Prevention growth charts. Blood was obtained by a finger prick under aseptic conditions and the haemoglobin level was determined using a field haemoglobin analyzer. Intestinal parasites such as hookworms, roundworms or microscopic parasites (Hymenolepis nana, Giardia intestinalis and Ascaris lumbricö̈des were detected) and bilharzia (urinary schistosomiasis due to Schistosoma haematobium) were detected using WHO recommended methods ${ }^{22}$. As these procedures (collecting feces or urine) are demanding for the children and families, these variables were only collected at the baseline. However, no significant differences were found between the Fulani and the non-Fulani at the baseline and all children were treated preventively for urinary and intestinal parasite diseases at the end of the baseline survey ${ }^{23}$. Note that including other parasite baseline infections in the regression analysis does not affect our results but decreases the size of the sample for the reasons mentioned above.

\footnotetext{
${ }^{22}$ To detect a maximum number of intestinal parasite cases, three methods were used for the analysis: (i) direct analysis for detecting vegetative forms of protozoan, (ii) Kato-Katz technique (used for the detection of helminthes eggs such as Ascaris lumbricoïdes). (iii) Ritchie method, a quantitative method that allows low density of parasite eggs and cysts to be detected. For urinary helminthes, the test consists of detecting the presence of Schistosoma haematobium eggs in urine. The filtration method with a Whatman filter was used to quantify egg densities per milliliter of urine.

${ }^{23}$ At the baseline, we could not perform these tests for 49 and 57 pupils among the 296 participants (for intestinal and urinary tests respectively) due to refusals
} 


\subsection{Appendix B: Proof of propositions}

Proof of Proposition 1. The first order conditions of the optimization problem can be written as:

$$
\begin{aligned}
-u^{\prime}(w-[(e+\lambda) s(p)] n)+R\left[p v^{\prime}(R e)+(1-p) \delta v^{\prime}(\delta R e)\right] & =0 \\
-(e+\lambda) u^{\prime}(w-[(e+\lambda) s(p)] n)+[p v(R e)+(1-p) v(\delta R e)] & =0 .
\end{aligned}
$$

By replacing (6) in (7), we obtain that $e^{*}$ is the solution of:

$$
-(e+\lambda) R\left[p v^{\prime}(R e)+(1-p) \delta v^{\prime}(\delta R e)\right]+[p v(R e)+(1-p) v(\delta R e)]=0 .
$$

We immediately conclude that

$$
\left.\frac{d e}{d w}\right|_{e=e^{*}}=0
$$

which proves the first claim of the proposition. By applying the implicit function theorem to (8), we can compute the derivative of $e^{*}$ with respect to $\lambda$ and $p$ and obtain:

$$
\begin{aligned}
& \left.\frac{d e}{d \lambda}\right|_{e=e^{*}}=\frac{-R\left[p v^{\prime}(R e)+(1-p) \delta v^{\prime}(\delta R e)\right]}{\left(e^{*}+\lambda\right) R^{2}\left[p v^{\prime \prime}\left(R e^{*}\right)+(1-p) \delta^{2} v^{\prime \prime}\left(\delta R e^{*}\right)\right]}, \\
& \left.\frac{d e}{d p}\right|_{e=e^{*}}=\frac{-\left(e^{*}+\lambda\right) R\left[v^{\prime}\left(R e^{*}\right)-\delta v^{\prime}\left(\delta R e^{*}\right)\right]+\left[v\left(R e^{*}\right)-v\left(\delta R e^{*}\right)\right]}{\left(e^{*}+\lambda\right) R^{2}\left[p v^{\prime \prime}\left(R e^{*}\right)+(1-p) \delta^{2} v^{\prime \prime}\left(\delta R e^{*}\right)\right]} .
\end{aligned}
$$

For $\delta=1$, we immediately see that $d e^{*} / d p=0$. For $\delta>1$, we replace (6) and (7) in (11) to obtain:

$$
\left.\frac{d e}{d p}\right|_{e=e^{*}}=\frac{(e+\lambda) R \delta v^{\prime}(\delta R e)-v(\delta R e)}{(e+\lambda) p R^{2}\left[p v^{\prime \prime}(R e)+(1-p) \delta^{2} v^{\prime \prime}(\delta R e)\right]} .
$$

The sign of $d e^{*} / d p$ is thus the opposite of the one of

$$
f(\lambda)=(e(\lambda)+\lambda) R \delta v^{\prime}(\delta \operatorname{Re}(\lambda))-v(\delta \operatorname{Re}(\lambda))
$$

where $e(\lambda)$ denote the relationship between $e^{*}$ and $\lambda$, which is given by the implicit function (8). We first notice that the strict concavity of $v$ implies $x v^{\prime}(x)<v(x)$ and, thus $f(0)<0$. 
Second, using (10), we obtain:

$$
f^{\prime}(\lambda)=p R \delta \frac{v^{\prime \prime}(R e) v^{\prime}(\delta R e)-v^{\prime}(R e) \delta v^{\prime \prime}(\delta R e)}{\left[p v^{\prime \prime}(R e)+(1-p) \delta^{2} v^{\prime \prime}(\delta R e)\right]}
$$

Thus, we have for all $x>0$ :

$$
f^{\prime}(\lambda) \geq 0 \Leftrightarrow \frac{d\left(-\frac{x v^{\prime \prime}(x)}{v^{\prime}(x)}\right)}{d x} \leq 0 .
$$

We conclude that if the relative risk aversion is constant or increasing $f(\lambda)<0$ for all $\lambda \geq 0$. If the relative risk aversion is decreasing, we use a continuity argument to state that $f(\lambda)<0$ for $\lambda$ is sufficiently small.

Proof of Proposition 2. Let $e^{*}$, which is the solution of (8), be expressed as a function of the infection rate $e^{*}:=e(p)$ where $e^{\prime}(p)$ is given by (12). Using (7), the optimal fertility is given by:

$$
-(e(p)+\lambda) u^{\prime}(w-[(e(p)+\lambda) s(p)] n)+[p v(\operatorname{Re}(p))+(1-p) v(\delta \operatorname{Re}(p))]=0 .
$$

By applying the implicit function theorem, we compute:

$$
\frac{d n^{*}}{d w}=\frac{1}{(e(p)+\lambda) s(p)}>0
$$

which proves the first claim of the proposition. Similarly, we have:

$$
\frac{d n^{*}}{d p}=\frac{v(\delta \operatorname{Re}(p))-v(\operatorname{Re}(p))}{(e(p)+\lambda)^{2} s(p) u^{\prime \prime}(.)}-e^{\prime}(p) \frac{n}{(e(p)+\lambda)}-s^{\prime}(p) \frac{n}{s(p)} .
$$

Using the fact that $d e^{*} / d p=0$ if $\delta=1$ (that has been proved in the proof of Proposition 1), we obtain that

$$
\left.\frac{d n^{*}}{d p}\right|_{\delta=1}=-s^{\prime}(p) \frac{n}{s(p)}>0
$$

and we conclude by continuity. 


\subsection{Appendix C: Appendix Figures and Tables}

Figure A1: Average precipitations in Diankabou (1961-1990). Source: New et al. (2002b)

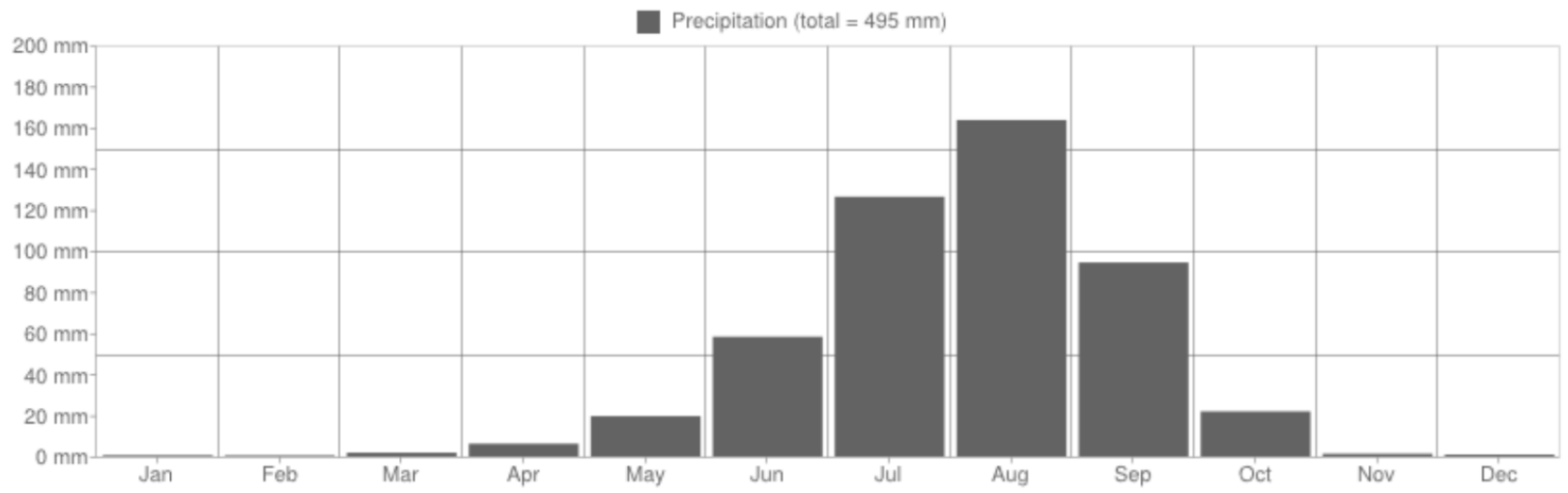


Figure A2: Density of Hemoglobin levels by Ethnic group over seasons (Diankabou)

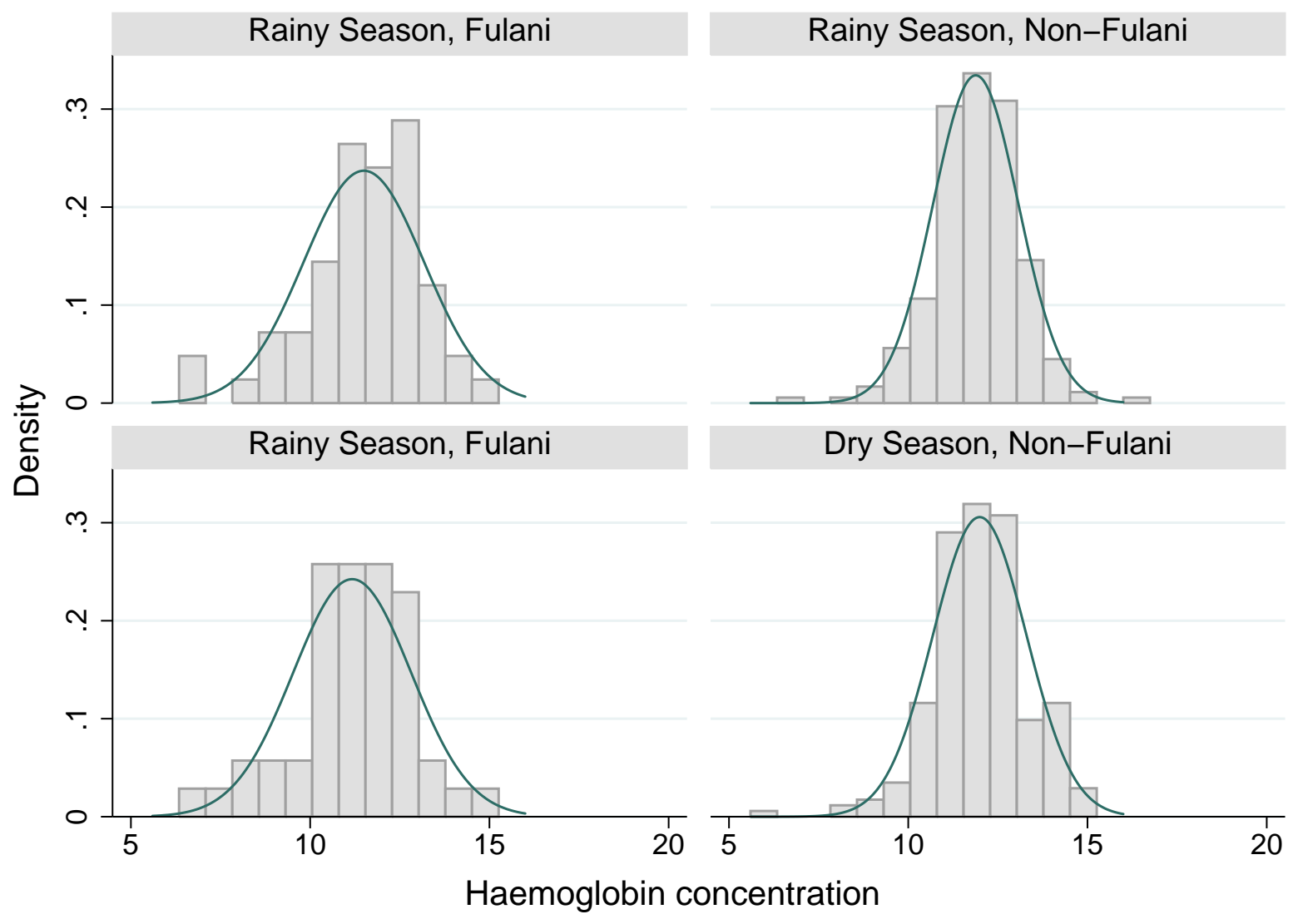


Figure A3: Density of Splenomegaly by Ethnic group over seasons (Diankabou)

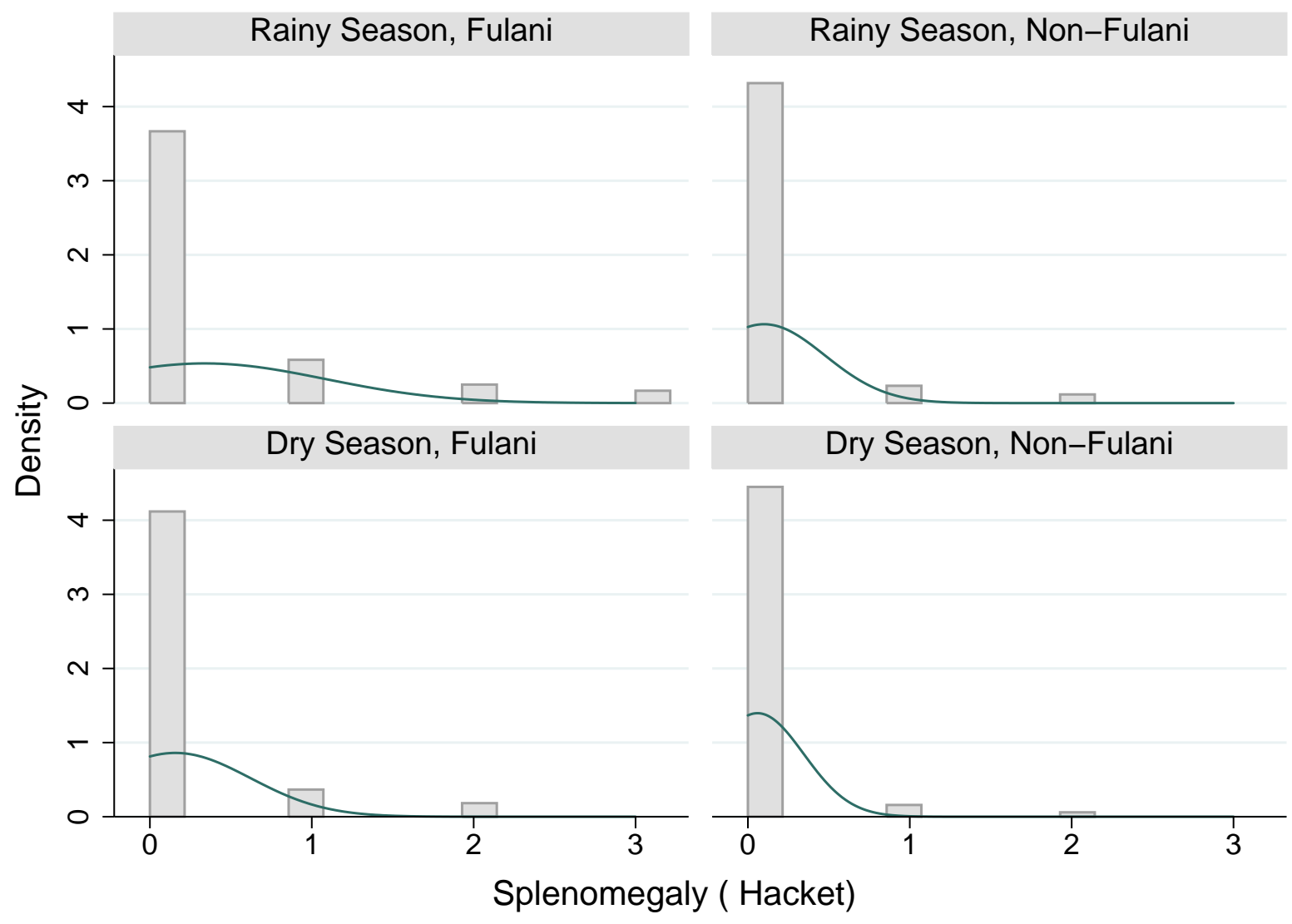


Figure A4: Density of BMI-for-age z-score by Ethnic group over seasons (Diankabou)

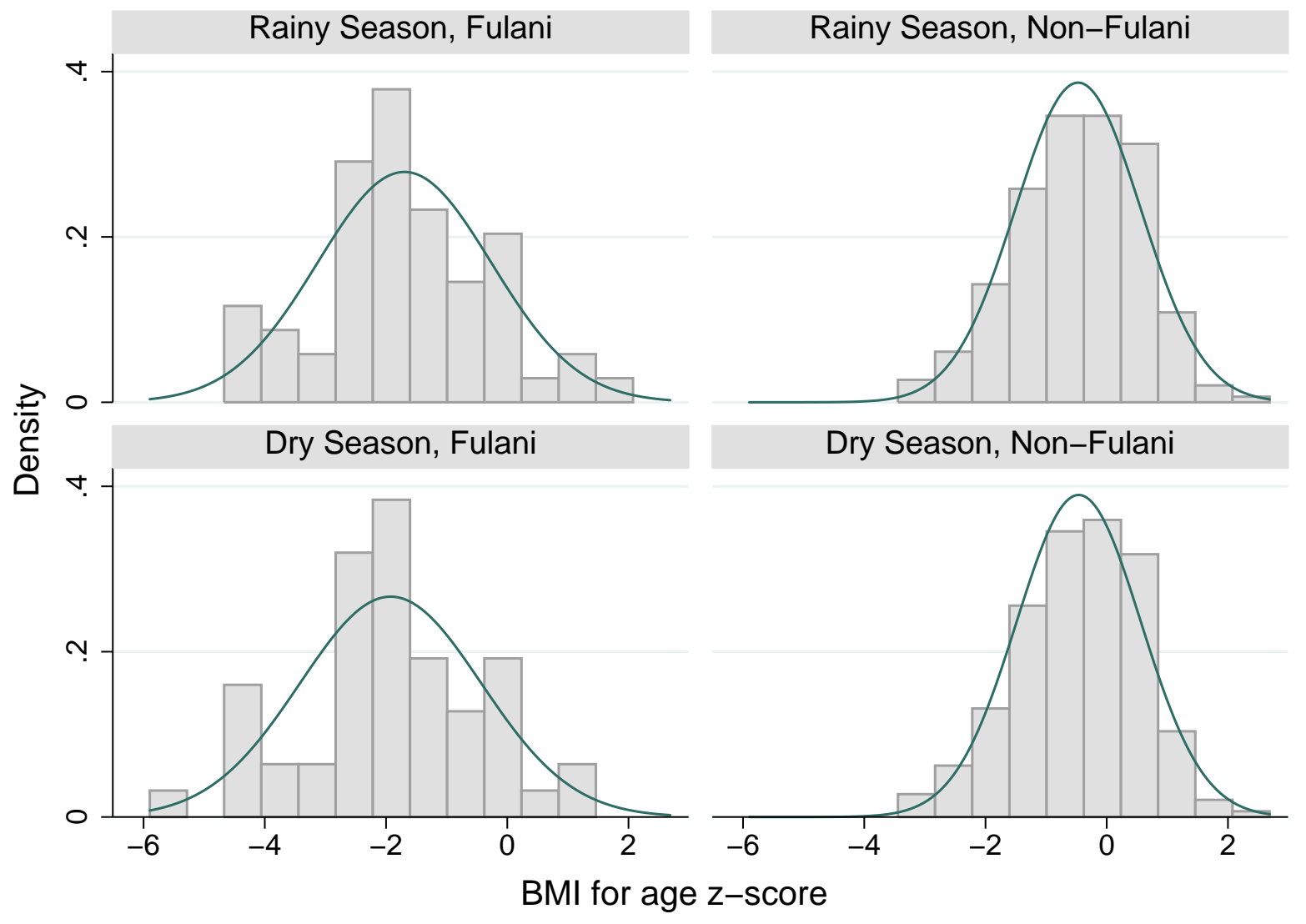


Figure A5: Density of Cognitive outcome by Ethnic group over seasons (Diankabou)

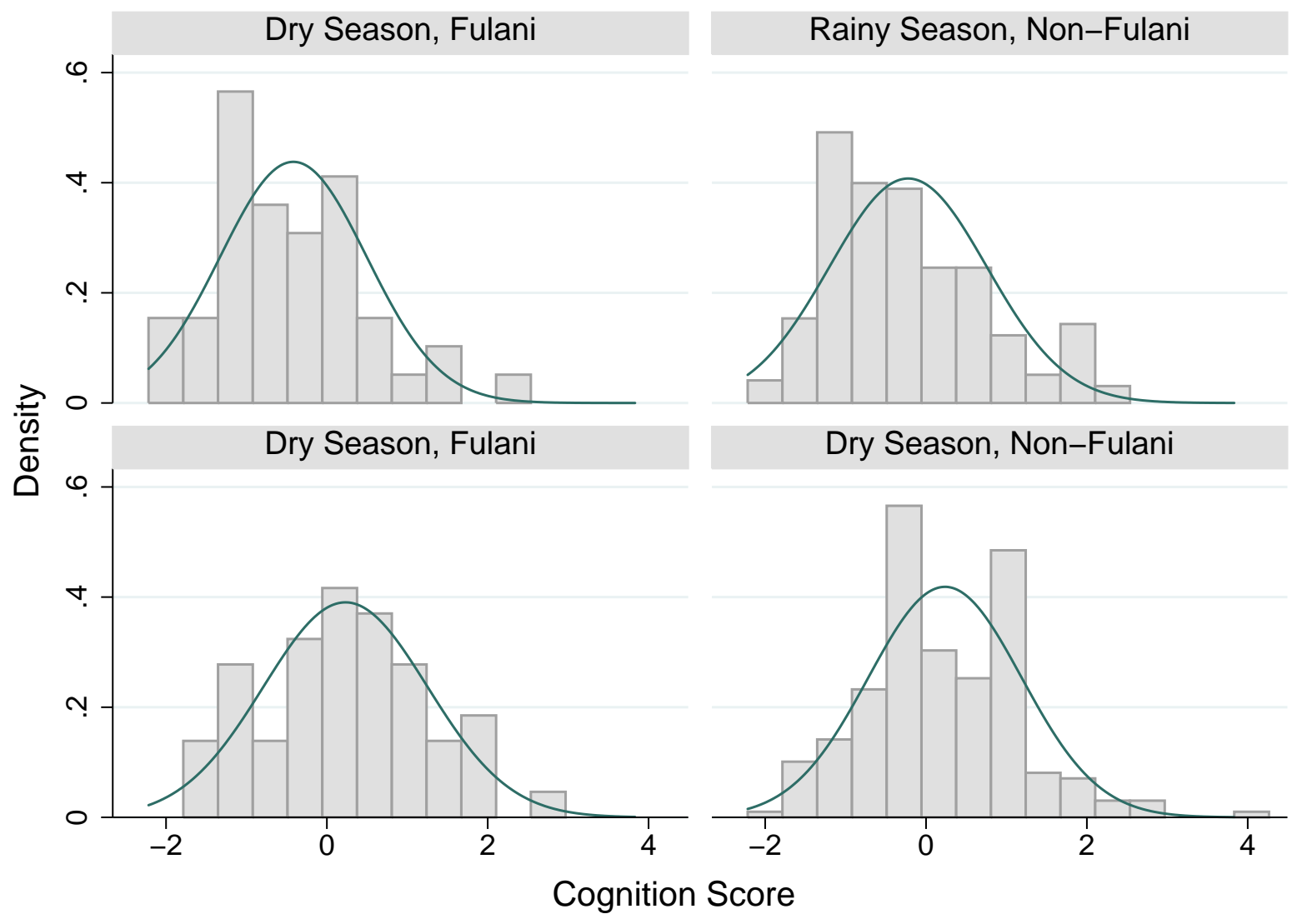


Figure A6: Density of Educational outcome by Ethnic group over seasons (Diankabou)

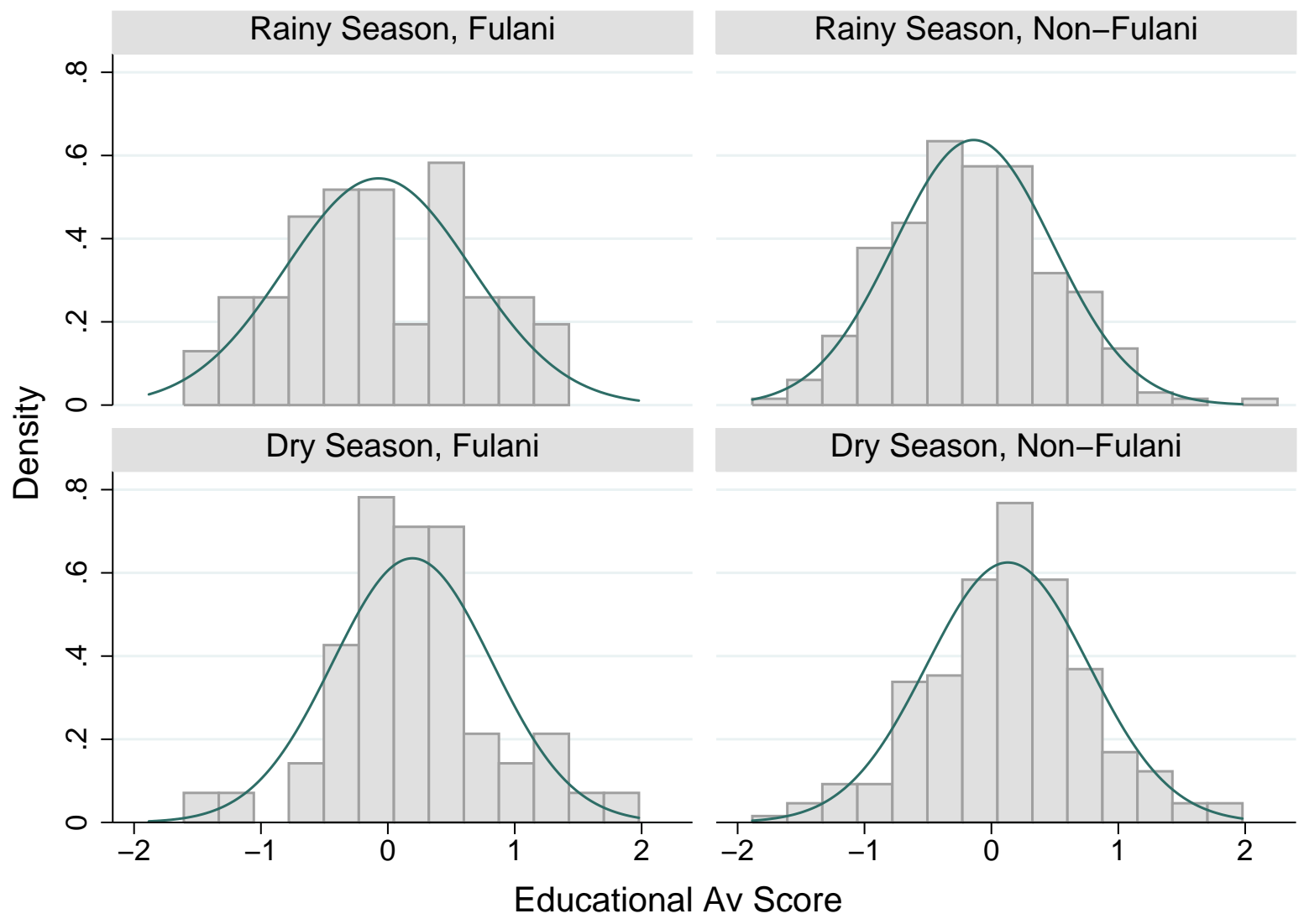


Figure A7: Fulani versus non-Fulani wealth index across seasons (source: Demographic and Health Survey (DHS) collected in 2001, 2006 and 2012-2013 in rural areas of the Mopti region)

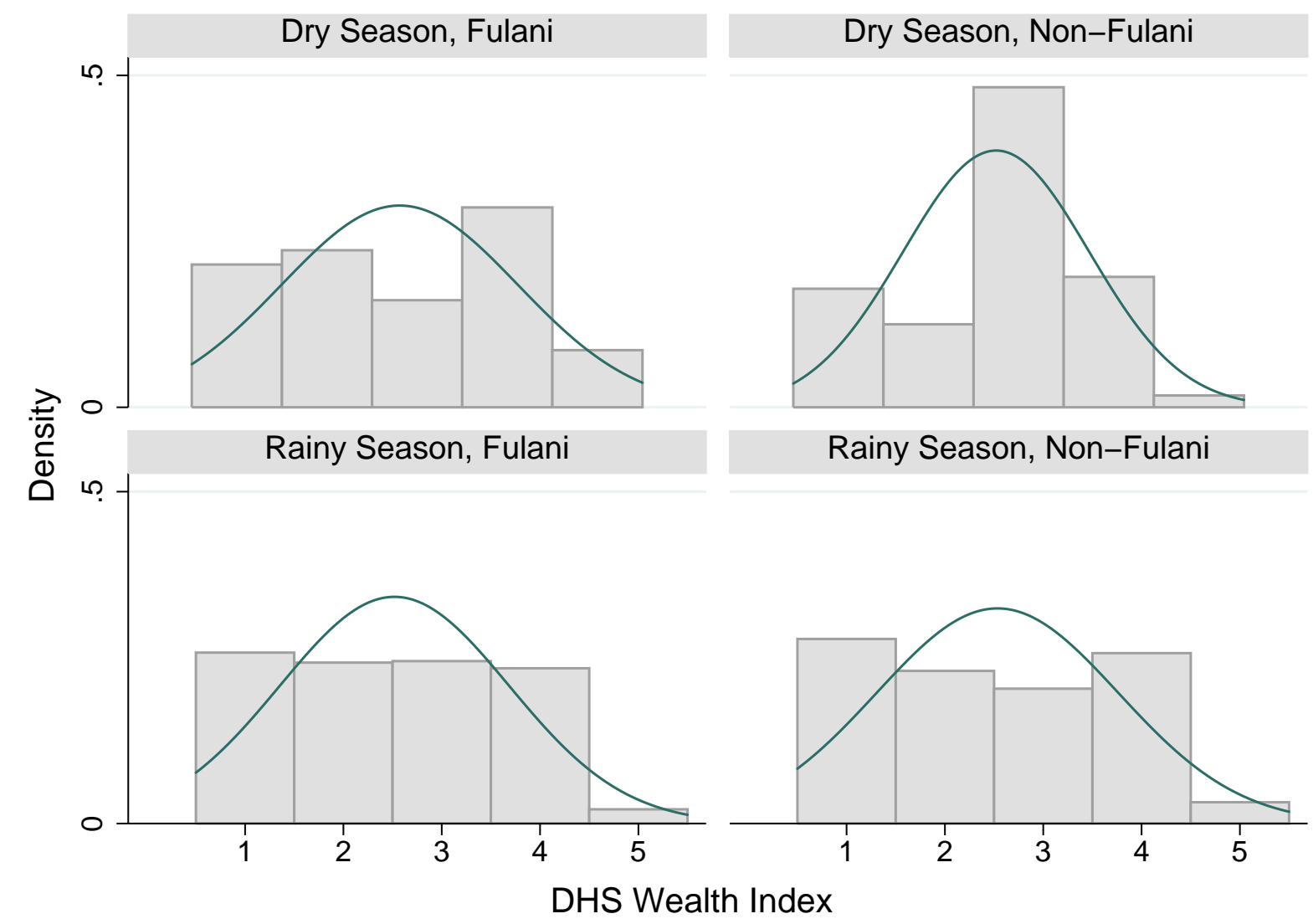

Notes: We compare the distribution of wealth for Fulani versus non-Fulani across seasons. t-test p-value comparing the two ethnic groups is 0.551 during the rainy season $(n=216)$ and 0.336 during the dry season $(n=773)$. t-test $\mathrm{p}$-value comparing the two seasons is 0.866 for Fulani $(\mathrm{n}=149)$ and 0.934 for non-Fulani $(\mathrm{n}=840)$. 
Figure A8: Possesion of bednet amongst Fulani versus non-Fulani across seasons (source: Demographic and Health Survey (DHS) collected in 2001, 2006 and 2012-2013 in rural areas of the Mopti region).

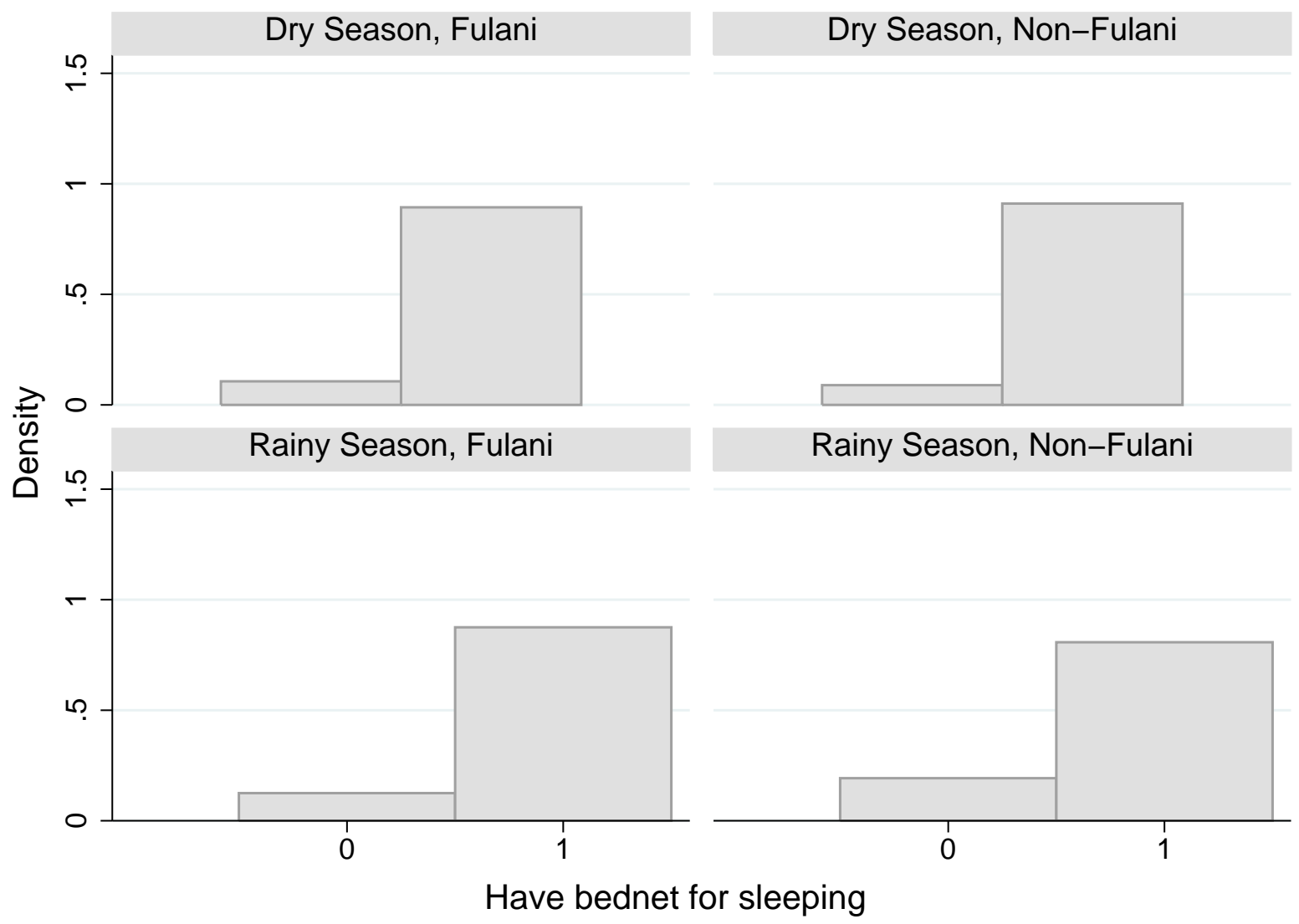

Notes: We compare the proportion of households having a bednet for sleeping as a proxy for healthcare access for Fulani versus non-Fulani across seasons. t-test p-value comparing the two ethnic groups is 0.208 during the rainy season $(\mathrm{n}=174)$ and 0.278 during the dry season $(\mathrm{n}=595)$. $\mathrm{t}$-test $\mathrm{p}$-value comparing the two seasons is 0.286 for Fulani $(\mathrm{n}=103)$ and 0.387 for non-Fulani $(\mathrm{n}=666)$. Note that we find similar results with bednet use. 
Table A1: Simple DiD with all controls

\begin{tabular}{|c|c|c|c|c|c|c|}
\hline & \multicolumn{5}{|c|}{ Whole Sample (Fulani \& Non Fulani) } & \multirow{2}{*}{$\begin{array}{l}\text { Fulani } \\
\text { \& Dogon only } \\
(6)\end{array}$} \\
\hline & $(1)$ & $(2)$ & $(3)$ & $(4)$ & $(5)$ & \\
\hline \multirow[t]{2}{*}{ Cognition score (Raven) } & -0.189 & -0.165 & -0.173 & -0.177 & -0.118 & -0.116 \\
\hline & $(0.227)$ & $(0.221)$ & $(0.228)$ & $(0.228)$ & $(0.282)$ & $(0.291)$ \\
\hline $\mathrm{N}$ & 550 & 550 & 550 & 542 & 504 & 474 \\
\hline $\mathrm{R} 2$ & 0.063 & 0.077 & 0.094 & 0.097 & 0.292 & 0.284 \\
\hline \multirow[t]{2}{*}{ Educational score (PCA score) } & -0.235 & -0.252 & -0.316 & -0.298 & -0.326 & -0.309 \\
\hline & $(0.239)$ & $(0.243)$ & $(0.250)$ & $(0.264)$ & $(0.298)$ & $(0.299)$ \\
\hline $\mathrm{N}$ & 504 & 504 & 503 & 498 & 430 & 402 \\
\hline $\mathrm{R} 2$ & 0.085 & 0.092 & 0.100 & 0.119 & 0.397 & 0.392 \\
\hline \multirow[t]{2}{*}{ Educational score (Av. score) } & 0.002 & -0.006 & -0.068 & -0.079 & -0.051 & -0.057 \\
\hline & $(0.109)$ & $(0.111)$ & $(0.114)$ & $(0.112)$ & $(0.117)$ & $(0.116)$ \\
\hline $\mathrm{N}$ & 583 & 583 & 582 & 574 & 556 & 526 \\
\hline $\mathrm{R} 2$ & 0.044 & 0.049 & 0.059 & 0.074 & 0.340 & 0.339 \\
\hline Malaria symptoms & No & Yes & Yes & Yes & Yes & Yes \\
\hline Health controls & No & No & Yes & Yes & Yes & Yes \\
\hline Wihtin Child fixed effects & No & No & No & No & Yes & Yes \\
\hline
\end{tabular}

Notes: This table provides the Average Treatment Effect using the simple DiD presented in equation (1) estimated with OLS and including all controls progressively (malaria controls, health controls, within child fixed effects). Each cell reports the coefficient from a separate regression where $\gamma_{1}$ is reported (the coefficient of the interaction term between Post $\times$ NonFulani. The last column reduces the sample to the Dogon ethnic group for the non-Fulani group whereas all other columns include all non-Fulani groups. Malaria controls include all malaria symptoms provided in Table 1 (five dummies for fever, cephalgia, vomiting, diarrhea, and abdominal pain. Health controls include splenomegaly, BMI-for-age, haemoglobin concentration. Standard errors are reported in parenthesis and clustered at the family level. Note that using other clustering options, e.g. at the ethnic level, does not change the results *,** and *** indicate significance at the 10,5 and $1 \%$ levels. 
Table A2: Effect Malaria on Cognitive and Educational Outcomes: Local Average Treatment Effect (using Microscopy based malaria infection instead of PCR).

\begin{tabular}{|c|c|c|c|c|c|c|}
\hline & \multicolumn{5}{|c|}{ Whole Sample (Fulani \& Non Fulani) } & \multirow{2}{*}{$\begin{array}{l}\text { Fulani } \\
\& \text { Dogon only } \\
(6)\end{array}$} \\
\hline & $(1)$ & $(2)$ & $(3)$ & $(4)$ & $(5)$ & \\
\hline \multicolumn{7}{|c|}{ Panel A: Malaria Microscopy (binary) } \\
\hline \multirow[t]{2}{*}{ Cognition score (Raven) } & -0.143 & $-0.790^{* * *}$ & $-0.705^{* * *}$ & $-0.747^{* * *}$ & $-0.961^{* * *}$ & $-0.952^{* * *}$ \\
\hline & $(0.090)$ & $(0.155)$ & $(0.146)$ & $(0.150)$ & $(0.173)$ & $(0.182)$ \\
\hline $\mathrm{N}$ & 544 & 544 & 544 & 536 & 494 & 464 \\
\hline $\mathrm{R} 2$ & 0.005 & - & - & - & - & - \\
\hline \multirow[t]{2}{*}{ Educational score (PCA score) } & $-0.481^{* * *}$ & $-1.429^{* * *}$ & $-1.352^{* * *}$ & $-1.391^{* * *}$ & $-1.384^{* * *}$ & $-1.418^{* * *}$ \\
\hline & $(0.113)$ & $(0.210)$ & $(0.213)$ & $(0.211)$ & $(0.200)$ & $(0.212)$ \\
\hline $\mathrm{N}$ & 498 & 498 & 498 & 493 & 422 & 394 \\
\hline R2 & 0.029 & - & - & - & - & - \\
\hline \multirow[t]{2}{*}{ Educational score (Av. score) } & $-0.165 * * *$ & $-0.518^{* * *}$ & $-0.478^{* * *}$ & $-0.513^{* * *}$ & $-0.503^{* * *}$ & $-0.501^{* * *}$ \\
\hline & $(0.051)$ & $(0.087)$ & $(0.083)$ & $(0.080)$ & $(0.079)$ & $(0.083)$ \\
\hline $\mathrm{N}$ & 575 & 575 & 575 & 567 & 544 & 514 \\
\hline $\mathrm{R} 2$ & 0.015 & - & - & - & - & - \\
\hline \multicolumn{7}{|c|}{ Panel B: Malaria Microscopy (continuous parasitaemia) } \\
\hline \multirow[t]{2}{*}{ Cognition score (Raven) } & 0.000 & $-0.005^{* * *}$ & $-0.004^{* *}$ & $-0.003^{*}$ & $-0.009^{* * *}$ & $-0.009^{* * *}$ \\
\hline & $(0.000)$ & $(0.002)$ & $(0.002)$ & $(0.001)$ & $(0.003)$ & $(0.003)$ \\
\hline $\mathrm{N}$ & 544 & 544 & 544 & 536 & 494 & 464 \\
\hline $\mathrm{R} 2$ & 0.001 & - & - & - & - & - \\
\hline \multirow[t]{2}{*}{ Educational score (PCA score) } & 0.000 & $-0.008^{* * *}$ & $-0.008^{* * *}$ & $-0.006^{* * *}$ & $-0.011^{* * *}$ & $-0.011^{* * *}$ \\
\hline & $(0.000)$ & $(0.003)$ & $(0.003)$ & $(0.002)$ & $(0.004)$ & $(0.004)$ \\
\hline $\mathrm{N}$ & 499 & 499 & 498 & 493 & 422 & 394 \\
\hline $\mathrm{R} 2$ & 0.001 & - & - & - & - & - \\
\hline \multirow[t]{2}{*}{ Educational score (Av. score) } & 0.000 & $-0.003^{* * *}$ & $-0.003^{* * *}$ & $-0.002^{* * *}$ & $-0.004^{* * *}$ & $-0.004^{* * *}$ \\
\hline & $(0.000)$ & $(0.001)$ & $(0.001)$ & $(0.001)$ & $(0.001)$ & $(0.001)$ \\
\hline $\mathrm{N}$ & 576 & 576 & 575 & 567 & 544 & 514 \\
\hline $\mathrm{R} 2$ & 0.001 & - & - & - & - & - \\
\hline OLS & Yes & No & No & No & No & No \\
\hline 2SLS & No & Yes & Yes & Yes & Yes & Yes \\
\hline Malaria symptoms & No & Yes & Yes & Yes & Yes & Yes \\
\hline Health controls & No & No & Yes & Yes & Yes & Yes \\
\hline Wihtin Child fixed effects & No & No & No & No & Yes & Yes \\
\hline
\end{tabular}

Notes: This table reproduces Table 2 but uses microscopy-based malaria measures. Each cell reports the coefficient from a separate regression corresponding to equation (2) where the first stage is equation (3), provided in Table 4. The measure used for malaria is the PCR measure. We provide similar tables for the other malaria (microscopy either binary or continuous) in Table A1 and A2. The last column reduces the sample to the Dogon ethnic group for the non-Fulani group whereas all other columns include all non-Fulani 
groups. Malaria controls include all malaria symptoms provided in Table 1 (five dummies for fever, cephalgia, vomiting, diarrhea, and abdominal pain. Health controls include splenomegaly, BMI-for-age, haemoglobin concentration. Standard errors are reported in parenthesis and clustered at the family level. Note that using other clustering options, e.g. at the ethnic level, does not change the results. ${ }^{*},{ }^{* *}$ and ${ }^{* * *}$ indicate significance at the 10,5 and $1 \%$ levels. 
Table A3: Estimating interactions of pre-seasonal differences and malaria on cognitive and educational outcomes.

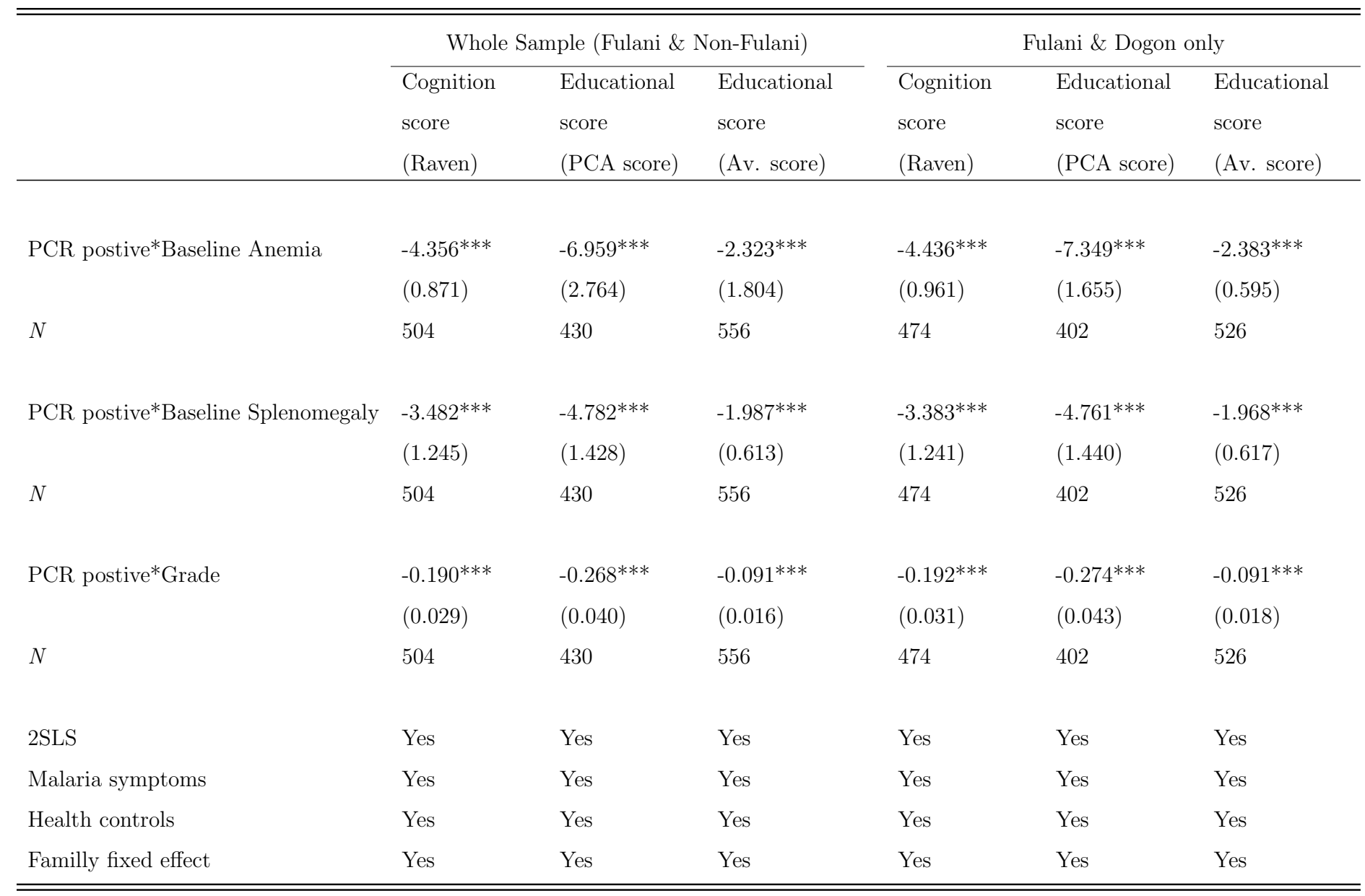

Notes: This table provides the Local Average Treatment Effect. Each cell reports the coefficient from a separate regression corresponding to equation (2) where we instrument both malaria and the additional health variables simultaneously following equation (3) where two health factors are considered as endogenous. The measure used for malaria is the PCR measure. The last column reduces the sample to the Dogon ethnic group for the non-Fulani group whereas all other columns include all non-Fulani groups. Standard errors are reported in parenthesis and clustered at the family level. Note that using 
other clustering options, e.g. at the ethnic level, does not change the results $*, * *$ and $* * *$ indicate significance at the 10,5 and $1 \%$ levels. 
Table A4: Local Average Treatment effect in another village in Mali.

\begin{tabular}{|c|c|c|c|c|c|}
\hline & \multicolumn{5}{|c|}{ Whole Sample (Fulani \& Non Fulani) } \\
\hline & $(1)$ & $(2)$ & $(3)$ & $(4)$ & $(5)$ \\
\hline \multicolumn{6}{|c|}{ Panel A: Malaria Microscopy (binary variable) } \\
\hline \multirow[t]{2}{*}{ Educational score (see Thuilliez et al., 2010) } & -0.084 & $-4.826^{* * *}$ & $-5.127^{* * *}$ & $-5.483^{* * *}$ & $-7.435^{* * *}$ \\
\hline & $(0.069)$ & $(0.646)$ & $(0.725)$ & $(0.824)$ & $(0.946)$ \\
\hline $\mathrm{N}$ & 1794 & 1794 & 1794 & 1794 & 1794 \\
\hline $\mathrm{R} 2$ & 0.001 & - & - & - & - \\
\hline \multicolumn{6}{|c|}{ Panel B: Malaria Microscopy (continuous parasitaemia) } \\
\hline \multirow[t]{2}{*}{ Educational score (see Thuilliez et al., 2010) } & $-0.000^{* * *}$ & $-0.001^{* * *}$ & $-0.001^{* * *}$ & $-0.001^{* * *}$ & $-0.001^{* * *}$ \\
\hline & $(0.000)$ & $(0.000)$ & $(0.000)$ & $(0.000)$ & $(0.000)$ \\
\hline $\mathrm{N}$ & 1794 & 1794 & 1794 & 1794 & 1794 \\
\hline $\mathrm{R} 2$ & 0.001 & - & - & & - \\
\hline OLS & Yes & No & No & No & No \\
\hline 2SLS & No & Yes & Yes & Yes & Yes \\
\hline Malaria symptoms & No & Yes & Yes & Yes & Yes \\
\hline Health controls & No & No & Yes & Yes & Yes \\
\hline Wihtin Child fixed effects & No & No & No & No & Yes \\
\hline
\end{tabular}

Notes: This table provides the Local Average Treatment Effect in another village in Mali using the same procedure as in Table 2. Each cell reports the coefficient from a separate regression corresponding to equation (2) where the first stage is equation (3). The measure used for malaria is microscopy, either binary or continuous. The last column reduces the sample to the Dogon ethnic group as the non-Fulani group whereas all other columns include all non-Fulani groups. Malaria controls include all malaria symptoms provided in Table 1 (five dummies for fever, cephalgia, vomiting, diarrhea, and abdominal pain. Health controls include splenomegaly, BMI-for-age, haemoglobin concentration. Standard errors are reported in parenthesis and clustered at the family level. Note that using other clustering options, e.g. at the ethnic level, does not change the results. ${ }^{*},{ }^{*}$ and $* * *$ indicate significance at the 10,5 and $1 \%$ levels. 